GEORGE A. AKERLOF

Brookings Institution and University of California, Berkeley

WILLIAM T. DICKENS

Brookings Institution

GEORGE L. PERRY

Brookings Institution

\title{
The Macroeconomics of Low Inflation
}

THE CONCEPT of a natural unemployment rate has been central to most modern models of inflation and stabilization. According to these models, inflation will accelerate or decelerate depending on whether unemployment is below or above the natural rate, while any existing rate of inflation will continue if unemployment is at the natural rate. The natural rate is thus the minimum, and only, sustainable rate of unemployment, but the inflation rate is left as a choice variable for policymakers. Since complete price stability has attractive features, many economists and policymakers who accept the natural rate hypothesis believe that central banks should target zero inflation.

We question the standard version of the natural rate model and each of these implications. Central to our analysis is the effect of downward nominal wage rigidity in an economy in which individual firms experience stochastic shocks in the demand for their output. We embed these features in a model that otherwise resembles a standard natural rate model and show there is no unique natural unemployment rate. Rather, the rate of unemployment that is consistent with steady inflation

We would especially like to thank Neil Siegel, Justin Smith, and Jennifer Eichberger for invaluable research assistance. We are also grateful to Pierre Fortin, Harry Holzer, and Christina Romer for providing us with data, and to John Baldwin, Paul Beaudry, Bryan Caplan, Bradford De Long, Erica Groshen, Peter Howitt, Shulamit Kahn, Kenneth McLaughlin, Craig Riddell, David Romer, Paul Romer, Charles Schultze, Lars Svensson, Robert Solow, and Michael Wolfson for their help and comments. George Akerlof also expresses his gratitude for the financial support of the Canadian Institute for Advanced Research and of the National Science Foundation under research grant SBR-9409426. 
itself depends on the inflation rate. In the long run, a moderate steady rate of inflation permits maximum employment and output. Maintenance of zero inflation measurably increases the sustainable unemployment rate and correspondingly reduces the level of output. We show that these effects are large, not negligible as some previous studies have claimed.

The view that unemployment will settle at a fixed natural rate if any steady rate of inflation is maintained is presumably the rationale for the Economic Growth and Price Stability Act of 1995, proposed by Senator Connie Mack. According to the preamble of this bill, "because price stability leads to the lowest possible interest rates and is a key condition to maintaining the highest possible levels of productivity, real incomes, living standards, employment, and global competitiveness, price stability should be the primary long-term goal of the Board of Governors of the Federal Reserve System."' But as our results show, a target of zero inflation will impose permanent real costs on the economy rather than the real benefits this preamble describes.

Although the appealing simplicity of the assumptions underlying natural rate models has put them in the forefront of macroeconomic modeling, there is ample precedent for our attention to downward wage rigidity and efficient employment levels, not only among labor economists but also in earlier macroeconomic models of inflation. James Tobin stressed their importance in his 1971 presidential address to the American Economic Association, in which he presented a model based on nominal rigidity that "implies a long-run Phillips curve that is very flat for high unemployment and becomes vertical at a critically low rate of unemployment." Indeed, in the first Phillips curve paper written in the United States, Paul Samuelson and Robert Solow had noted that "downward inflexibility keeps prices from falling. . . . The result is an upward drift in average prices-with the suggestion that monetary and fiscal policies restrictive enough to prevent an average price rise would have to be so very restrictive as to produce a considerable level of unemployment and a significant drop in production." They, in turn, were reflecting on the "demand shift"' theory of Charles Schultze, who

1. Quoted in U.S. Congress, Joint Economic Committee, "Statement by Connie Mack on the Economic Growth and Price Stability Act," news release, September 20, 1995. 
stressed that "creeping inflation is associated with the dynamics of resource allocation.,",2

The plan of the paper is as follows. We start with a review of ethnographic evidence that points to reasons why rational firms would want to avoid cutting nominal wages, and then provide a range of evidence establishing empirically that nominal wage cuts are rare, except when firms are under extreme financial strain. This evidence includes comprehensive data on U.S. manufacturing establishments, data on both Canadian and U.S. union wage settlements, employers' reports from special studies, and our own telephone survey of individuals in the Washington, D.C., area. We also examine recent studies based on panel data that measure wage changes as the first difference in reported wage levels from consecutive survey years. These estimates of wage changes suggest that wage cuts are frequent, seemingly contradicting the findings from other sources. However, we show that the apparent frequency of wage cuts in the panel data is spurious, because many of the apparent wage cuts arise from errors in reported wage levels.

Having established the empirical importance of downward wage rigidity, we present a formal model that reflects optimizing behavior of firms that explicitly allows for downward wage rigidity under all but extreme circumstances and takes account of heterogeneous wage setting by firms. Relative to previous attempts to assess the consequences of downward wage rigidity, our innovations multiply the calculated losses in employment and output from low inflation policies in three ways. First, our interpretations of the evidence on wage rigidity lead us to model nominal wage cuts as much less likely than do other authors. Second, we show that the effects of constraints are cumulative in a heterogeneous dynamic model, where firms that raise wages in response to favorable shocks in one period are more likely to be constrained by downward rigidity in subsequent periods. And third, we provide a general-equilibrium solution in which the impact on wages of downward wage constraints acts like a real cost shock, which the constrained firms pass on, in terms of higher prices.

General-equilibrium and partial-equilibrium analyses produce very

2. Tobin (1972, p. 11); Samuelson and Solow (1960, p. 182); Schultze (1959, p. 134). 
different estimates of the consequences of targeting zero inflation. Both analyses begin with an estimate of the shift in the aggregate supply of labor because of nominal wage rigidity. Partial-equilibrium analysis then multiplies the shift between the real wage with and without nominal wage rigidity by the elasticity of demand for labor to obtain the impact of downward wage rigidity on the level of employment. Typically, this elasticity of demand is assumed to be fairly low-less than one.

General-equilibrium analysis follows the impact of downward wage rigidity beyond the labor demand of the individual firms with downward wage constraints. The special case of constant product elasticities of demand is not essential to the argument, but makes it easy to highlight the difference between general-equilibrium and partial-equilibrium analysis. Firms whose nominal wages are raised by constraints pass on their increased costs in higher prices. The markup is constant, because of constant elasticity of demand, and so the average real wage will be unchanged by the impact of wage constraints. The real average wage has two components. The first component is the unconstrained real wage that results from labor supply and demand or bargaining, and is a function of the unemployment rate. The other component of real wages is due to downward wage rigidity. When this component increases, unemployment must increase by enough to lower the unconstrained component equally, to keep average real wages constant. The increase in the component due to downward rigidity can be thought of as a permanent cost shock. Typically, it takes a 2 percent increase in unemployment to offset such a 1 percent cost shock. Our analysis produces such a multiplier.

We develop a stochastic simulation based on our general-equilibrium model. This simulation is calibrated to conform to data on the U.S. economy. We use it to examine the performance of the economy at alternative steady rates of inflation. We calibrate the model to have an unemployment rate of 5.8 percent at 3 percent inflation because this seems to be the typical estimate of the present natural rate. But performance changes nonlinearly as the steady inflation rate approaches zero, and at zero inflation the sustainable unemployment rate is noticeably higher. In a large number of simulations using different parameter values, the change in the sustainable unemployment rate is rarely less than 1 percentage point. 
We also develop a version of the model that is suitable to estimation with time-series data. It embeds the features of the simulation model in an otherwise conventional natural rate model of inflation, allowing for parameters to be estimated from time-series data. When the model is fit to postwar data, the estimated parameters are reasonably consistent with the counterpart concepts in the simulation model, and the calculated values of sustainable unemployment rates vary with inflation rates in much the same way as they do in the simulation model. We then show that a dynamic simulation of the model fit to postwar data closely tracks price changes during the Great Depression, a period that notoriously defies explanation with conventional natural rate models.

\section{Evidence on Downward Rigidity}

Our own reading of the evidence, and the fundamental assumption of the model that we develop below, is that nominal wages are downward rigid, except when firms are under extreme duress. Twenty-five years ago, that hypothesis would have been widely accepted and could have been employed in a macroeconomic model without specific empirical support. Since then, it has come to be ignored in theoretical macroeconomic models, and its empirical importance has recently been questioned by some authors on the basis of panel data on wage changes. We present a range of evidence demonstrating that downward rigidity is an important feature of wage behavior, and then show that contrary results from panel data are spurious, because they arise from errors made by respondents in reporting their wage levels. But first we discuss various studies that suggest why downward wage rigidity is likely to be a feature of wage setting.

\section{Ethnographic Evidence}

Ethnographic observation by Truman Bewley and William Brainard provides direct evidence on the attitudes of employers toward wage cuts. ${ }^{3}$ In 1992, Bewley and Brainard interviewed businesspeople and others professionally involved in the job market in Connecticut, in-

3. Bewley and Brainard (1993); Bewley (1994). 
quiring specifically about the reluctance to cut wages and the reasons behind the wage cuts that do occur. They discovered that pay cuts were only an infrequent response to declines in sales, and that managers were much more fearful of the effects on morale caused by a cut in pay than by a wage freeze, which leaves real wages declining by the rate of inflation. The previous two years had been difficult for firms in the region, and the authors did find instances of wage cuts. In their sample of sixty-one firms, five had initiated cuts for some or all of their workers in the recent past, while the managers of six more firms could remember cuts during the last ten years. An additional eleven firms had initiated wage freezes. Of the eleven firms that reported cutting wages at some time in their history, most, but not quite all, had done so in response to serious problems. And in two cases, the cuts had been rescinded within six months.

Looking at the circumstances surrounding the pay cuts, Bewley and Brainard describe one firm that cut wages as having had losses for three years, another as doing so in 1991 in response to losses that began in 1989 , another in response to "cash flow problems," another because its sales suddenly "fell off a cliff," and yet another because it was "in danger of going out of business." These firms instigated nominal wage cuts, and workers accepted them, only when the firms faced the prospect of bankruptcy. In two other instances, wages were cut because they were perceived as having gotten permanently out of line. One store had allowed its sales force to build up the base rate of pay as an incentive to achieve high volume, with the result that incentive pay for sales had become too low. It used the recession as an opportunity to reestablish the balance between commissions and base pay. The other readjustment of long-term wages occurred when a raider took over a plant in the South. The previous owner had maintained parity between this plant, which was not unionized, and its other, unionized establishments. The new owner took advantage of the disparity between union wages and competitive wages to make a 15 percent wage cut at the time of takeover. Overall, Bewley and Brainard paint a picture in which firms cut wages only reluctantly.

The attitudes of employers that Bewley and Brainard report support the well-known study of popular conceptions of fairness by Daniel Kahneman, Jack Knetsch, and Richard Thaler. They show that most 
people feel that nominal pay cuts are unfair, except in unusual circumstances such as the near-bankruptcy of their employers. Respondents were asked whether they viewed a number of different actions as fair or unfair. Sixty-two percent considered that it would be unfair for a company making a small profit to decrease wages by 7 percent if inflation were zero. In contrast, if inflation were 12 percent, only 22 percent of respondents thought that a raise of only 5 percent would be unfair. ${ }^{4}$ Eldar Shafir, Peter Diamond, and Amos Tversky produce similar findings in their study of money illusion. ${ }^{5}$ Their questions show that interviewees do not like wage cuts; they prefer situations in which nominal wages rise, even though the real consequences are the same.

A recent study by Carl Campbell and Kunul Kamlani examines the reasons why firms are reluctant to reduce wages in recessions. ${ }^{6} \mathrm{Com}-$ pensation professionals at larger firms and wage setters from smaller firms were asked to evaluate the importance of different reasons for the reluctance to make wage cuts in recessions. They gave the most weight to the potential loss of the most productive workers (who, presumably, were receiving lower wages relative to productivity than their coworkers) and the effect on the motivation of workers who received wage cuts. Confirming the earlier findings of Kahneman, Knetsch, and Thaler, the respondents thought that workers whose wages were cut at firms with losses would decrease their efforts by less than their counterparts at firms earning profits. Those who might expect that norms against nominal wage cuts only apply to blue collar workers would be surprised to learn that these compensation professionals thought that the effect on productivity would, in fact, be more significant for white collar workers.

Bewley and Brainard directly document the importance attached to avoiding nominal wage cuts, except as an extreme measure, when a firm is in serious trouble. Kahneman, Knetsch, and Thaler and Campbell and Kamlani provide reasons why rational employers would behave in this way. We now turn to quantitative evidence on the importance of downward rigidity in nominal wages.

4. Kahneman, Knetsch, and Thaler (1986, p. 731, questions 4A and 4B).

5. Shafir, Diamond, and Tversky (1994).

6. Campbell and Kamlani (1995). 
Table 1. General Wage Changes in Manufacturing, 1959-78

Percent, production and related workers

\begin{tabular}{cccccccc}
\hline & \multicolumn{3}{c}{ Union } & & \multicolumn{3}{c}{ Nonunion } \\
\cline { 2 - 3 } \cline { 6 - 7 } Year & Increase & No change & Decrease & & Increase & No change & Decrease \\
\hline 1959 & 87.0 & 12.9 & 0.0 & 68.6 & 31.4 & 0.0 \\
1960 & 87.1 & 12.8 & 0.1 & & 59.0 & 41.0 & 0.0 \\
1961 & 83.3 & 16.6 & 0.1 & & 54.0 & 45.6 & 0.4 \\
1962 & 72.8 & 27.1 & 0.1 & & 52.9 & 47.1 & 0.0 \\
1963 & 77.8 & 22.0 & 0.2 & & 69.6 & 30.2 & 0.2 \\
1964 & 76.1 & 23.9 & 0.1 & & 56.2 & 43.8 & 0.0 \\
1965 & 87.3 & 12.7 & 0.0 & & 75.4 & 24.6 & 0.0 \\
1966 & 80.9 & 19.1 & 0.0 & & 77.8 & 22.2 & 0.0 \\
1967 & 90.6 & 9.4 & 0.0 & & 81.1 & 18.9 & 0.0 \\
1968 & 93.7 & 6.3 & 0.0 & & 87.6 & 12.4 & 0.0 \\
1969 & 93.2 & 6.8 & 0.0 & & 75.5 & 24.5 & 0.0 \\
1970 & 94.8 & 5.2 & 0.0 & & 77.6 & 22.4 & 0.0 \\
1971 & 92.0 & 8.0 & 0.0 & & 70.2 & 29.4 & 0.4 \\
1972 & 92.9 & 7.1 & 0.0 & & 83.2 & 16.8 & 0.1 \\
1973 & 95.9 & 4.1 & 0.0 & & 90.1 & 9.9 & 0.0 \\
1974 & 97.8 & 2.2 & 0.0 & & 89.1 & 10.7 & 0.3 \\
1975 & 97.3 & 2.7 & 0.0 & & 84.7 & 15.3 & 0.0 \\
1976 & 96.9 & 3.1 & 0.0 & 88.4 & 11.6 & 0.0 \\
1977 & 96.1 & 3.9 & 0.0 & 84.8 & 15.2 & 0.0 \\
1978 & 96.6 & 3.4 & 0.0 & 89.3 & 10.7 & 0.0 \\
\hline
\end{tabular}

Source: Bureau of Labor Statistics, "Current Wage Developments," various issues.

\section{Wage Changes in Manufacturing}

From 1959 to 1978, the Bureau of Labor Statistics (BLS) collected data on the distribution of general wage changes in manufacturing establishments. These data are confined to production and related workers in establishments that make general wage changes, but in other respects are quite broad, covering establishments of all sizes and wages for both unionized and nonunionized workers. The results, summarized in table 1 , show that in any given year a considerable fraction of firms gave no general nominal wage increase in the low-inflation period of the early 1960 s, and among nonunion establishments, many gave no general increase even during the inflationary 1970 s. But in no year did a nontrivial fraction of these manufacturing establishments cut wages. The data show a pronounced asymmetry; the part of the tail of the distribution of wage changes below zero is almost completely truncated. These data are not available for the early 1980s, a period when wage concessions were reported in some conspicuously troubled industries. 


\section{Union Settlements}

BLS data for 1970 through 1994 on union settlements for private workers that involved more than one thousand workers provide another look at the frequency of wage cuts, and also at the unusual developments of the early 1980 s. In this period, wage cuts were common only in 1983 , when 15 percent of all settlements had negative changes in the first year. Even in this year there was considerable evidence of downward rigidity, in that 22 percent of all contracts had no wage change. In the preceding year, 42 percent of new contracts had freezes and 2 percent had wage cuts. This episode supports our view that downward rigidity is broken when firms are under extreme duress. The 1981-82 recession was particularly severe; unemployment peaked at over 10 percent, the highest level since the end of the Great Depression. Excluding 1983 from our sample, an average of only 1.7 percent of workers were involved in negative wage settlements in the first year of a contract, and this overstates the frequency of wage cuts in any given year, since there were fewer negative changes over the life of the contract than in the first year. Assuming an average contract life of two years, and if all wage cuts occur in the first year, the proportion of workers with negative changes in any one year would be only 0.9 percent. Most recently, from 1990 through 1994, only 2.2 percent of workers covered by new settlements took wage cuts, despite inflation in the CPI averaging only 3.6 percent.

A further check on the frequency of negative wage changes under conditions of very low inflation and high unemployment comes from Canadian data analyzed by Pierre Fortin. ${ }^{7}$ From 1992 to 1994 , Canada averaged 1.2 percent inflation (as measured by the CPI) and 11.0 percent unemployment. Fortin's tabulation of wage settlements in large collective agreements without COLA clauses shows that only 5.7 percent of such agreements had cuts, while 47.2 percent called for unchanged wages. This huge mass at zero demonstrates the undeniable importance of wage rigidity in Canadian contracts. In somewhat better times there were yet fewer cuts in base pay. From 1986 to 1988, for example, with 4.2 percent inflation and 8.8 percent unemployment,

7. Personal communication from Pierre Fortin, University of Quebec at Montreal, August 13, 1995. 
only 0.25 percent of such contracts had wage cuts, while 12.6 percent had wage freezes.

\section{Historical Evidence on Wage Rigidity}

Although evidence on wage rigidity before World War II is much harder to come by, some authors have tackled the job. Daniel J. B. Mitchell, in his study of changing wage flexibility, compares the postwar behavior of manufacturing wages discussed above with evidence on manufacturing wages from establishment surveys in the 1920s. Although he expresses reservations about the reliability of these early surveys, he concludes that downward wage rigidity was less characteristic of the $1920 \mathrm{~s}$, and suggests that it became prominent as a result of legal and institutional changes, especially the development and acceptance of modern labor relations practices, which, he argues, have their roots in the Great Depression. Anthony O'Brien, however, using information from trade and industry sources, establishes the existence of downward rigidity in the 1920s. He shows that employers were even reluctant to cut wages during the onset of the Great Depression, before the legal and institutional changes cited by Mitchell occurred, and he finds that this reluctance was overcome only after economic conditions worsened in the early 1930s. Christopher Hanes finds evidence of nominal wage rigidity in the recession that began in 1893, as well as in the early stages of the Great Depression. All three authors are testing modern theories of why firms would be reluctant to cut wages; none finds reason to question that firms had been reluctant to do so, even before the postwar period. ${ }^{8}$

\section{A Survey of Wage Changes}

In order to get direct evidence on wage changes for individuals, in the summer of 1995 we conducted a telephone survey of the Washington, D.C., area. In particular, we wanted to ask directly about wage changes in order to be able to compare our results with those of the Panel Study of Income Dynamics (PSID), which asks about wage levels. We judged that although many workers might not report accurately the amount of their base wage or salary each year, they would be able 
to recall whether their wage had changed in the last twelve months and, if so, whether it had increased or decreased. When respondents did report negative wage changes, we requested further information about the circumstances. If individuals are frequently moved into lower positions, it might be rare to see a wage reduction for a job classification, even though individuals correctly report that they have taken wage cuts. The questionnaire was designed to detect such a possibility.

In the core of the survey, respondents were first asked about their employment status, and, if employed, whether they had the same employer as one year ago. Those who had stayed with the same employer were then asked if their job title or classification had changed over the past year, and whether they were performing substantially the same duties as they had been a year ago. After the method of pay (for example, hourly wage, annualized salary) had been ascertained, respondents were asked, "Excluding overtime, commissions, and bonuses, has your base rate of pay changed since a year ago today?" Affirmative responses were followed with "Did it increase or decrease? By how much?" Additional demographic information, including age, race, and sector of employment, was then solicited.

We contacted a total of 569 individuals. Of the 409 respondents who had not changed employers and who were wage or salary earners, seven reported wage or salary cuts with no change in the circumstances of their job. Four of these were workers for the District of Columbia government, which then and now confronts a budget crisis; one was a construction worker who speculated that his employer had reduced wages and substituted illegal aliens for native-born workers; one was a railroad worker who was paid by the run and reported the rate had been reduced because of cutbacks; and one acted sufficiently intoxicated that the interviewer doubted whether any of the questions were being understood, before the respondent abruptly hung up. In addition to these seven, four other respondents reported a change in circumstances that resulted in a lower individual wage or salary, but not necessarily lower overall compensation, for the same job. Of these, two had been promoted from part-time to full-time employment over the course of the year; one explained that she had taken a decrease in wages but was more than compensated by an increase in benefits. The other two said that they had changed jobs within the firm.

The survey results, summarized in table 2 , show that only 2.7 percent 
Table 2. Job Stayers Reporting Changes in Base Pay in Previous Year Percent, except where indicated

\begin{tabular}{lcccc}
\hline & \multicolumn{3}{c}{ Reported change } & $\begin{array}{c}\text { Number of } \\
\text { respondents }\end{array}$ \\
\cline { 2 - 4 } & Negative & None & Positive & 409 \\
Total & 2.7 & 30.8 & 66.5 & 250 \\
$\quad$ Private & 2.4 & 34.0 & 63.6 & 159 \\
Public & 3.1 & 25.8 & 71.1 & 103 \\
Wage earners & 5.8 & 39.8 & 54.4 & 74 \\
$\quad$ Private & 4.0 & 41.9 & 54.1 & 29 \\
$\quad$ Public & 10.3 & 34.5 & 55.2 & 306 \\
Salaried and other & 1.6 & 27.8 & 70.6 & 176 \\
$\quad$ Private & 1.7 & 30.7 & 67.6 & 130 \\
Public & 1.5 & 23.8 & 74.6 &
\end{tabular}

Source: Authors' calculations from 1995 Washington area telephone survey, as described in text.

of respondents who had stayed at the same job had received wage cuts. This result does not depend on the large number of federal workers in the Washington area. In fact, only 2.4 percent of private sector workers reported wage cuts. Admittedly, the survey is not a representative sample of the national population, as it is confined to the Washington area and biased toward people who answered the telephone and were willing to answer our questions. Nonetheless, it suggests that the fraction of workers who receive wage cuts in any given year is small; with double the survey fractions, the numbers are still small. This conclusion is supported by the answers to another question on our survey: whether respondents personally knew anyone who had ever taken a cut in pay while on the same job. The meaning of these answers depends upon the universe of friends, relatives, and acquaintances of the respondents and on their memories. Nevertheless, if pay cuts were fairly common, we would expect that they could easily dredge up some instances. Yet only 14.7 percent of respondents recalled personal knowledge of a pay cut.

\section{Recent Panel Studies}

Four recent studies, by David Card and Dean Hyslop, David Lebow, David Stockton, and William Wascher, Shulamit Kahn, and Kenneth McLaughlin, have used data from the PSID to analyze wage change for individuals. ${ }^{9}$ In each case, the authors compute wage change as the

9. Card and Hyslop (1996); Lebow, Stockton, and Wascher (1995); Kahn (1995); McLaughlin (1994). 
difference between reported wage levels in consecutive years. All find evidence of asymmetry in the histograms of wage changes, and some bunching at zero change. But the histograms also show that in any year, a noticeable fraction of workers receive wage or salary cuts. If true, such a finding would greatly reduce the economic significance of downward rigidity. However, we show that the crude data cannot be interpreted in this way. Most of these negative changes are spurious; they arise because errors in the reporting of wage levels greatly exaggerate the actual frequency of wage cuts. All four studies are aware of the importance of reporting error. But, except for McLaughlin, the authors make no attempt to correct for the errors that we find important, and we find that McLaughlin's correction does not go nearly far enough. ${ }^{10}$

Validation studies of wage surveys similar to the PSID show that reporting errors are quite large. For example, the January 1977 validation study of the Current Population Survey (CPS) shows an estimated standard deviation of 0.167 in the difference between log wages reported by household respondents and those reported by their employers. ${ }^{11}$ With such a standard deviation, response error alone could easily account for all the observations of wage cuts in the PSID. We compare the findings using the PSID with other evidence to show this is, in fact, the case. ${ }^{12}$

10. McLaughlin presents corrected measures of the standard deviation of wage changes, and then infers the impact of the correction for the frequency of negative wage changes, using the empirical distribution of wage changes in the PSID. However, this is inappropriate if the underlying true distribution is asymmetric, as the distribution of wage changes appears to be. For example, suppose that the true distribution of wage changes contained no negative values. If a normal measurement error was added to the true values, a large number of false negative wage changes would be recorded. Simply reducing the variance of the empirical distribution by a mean-preserving reduction in the spread equal to the variance of the measurement error, as McLaughlin does, will reduce the frequency of false negatives but will not eliminate them. It is impossible to reconstruct the true underlying distribution in this fashion. Kahn recognizes the presence of errors but does not attempt to correct for them because doing so would only strengthen her conclusions about the presence of downward rigidity.

11. Mellow and Sider $(1983$, p. 335, n. 6) report that "the estimated variance of the difference in log wage is 0.167 ." Our calculations, based on regression estimates that they present, suggest approximately this figure for the standard deviation.

12. A validation survey for the PSID shows large errors in reported income, but since the plant chosen for the survey did not pay straight time wages, the accuracy of the PSID question on hourly earnings cannot be assessed (see Duncan and Hill, 1985). 


\section{Comparing Our Survey Data with the PSID}

Armed with our survey results, we check whether the PSID-generated data could have arisen from a population that resembles our survey, making appropriate allowance for reporting error in the PSID. To this end, we "dirty" our data by adding random errors corresponding to observed distributions of response errors in the CPS, in which questions about wages are quite similar to those in the PSID. To estimate the distribution of the response error in wage changes, we need to know not only the distribution of response error for wage levels in a single survey, but also the autocorrelation of those response errors across surveys and the frequency with which people report their wages correctly. The distribution of these response errors is generated with the help of three separate statistics. In the 1977 CPS validation survey, workers' wage responses are matched against responses of their employers and, as mentioned above, have a standard deviation of 0.167 in the difference between log wages reported by individuals and $\log$ wages reported by their respective employers. The CPS-social security match survey shows the autocorrelation of differences between earnings reported by CPS respondents and their individual earnings as reported to the Social Security Administration. ${ }^{13}$ These parameters would be sufficient to generate a normal distribution of response error, but one final consideration suggests that the errors are not normal: some respondents - in fact, 44.2 percent-report their wages or salaries exactly right. So we generate the error distribution under the assumption that 44.2 percent of respondents make no error in either year and the rest make normally distributed autocorrelated errors.

The alternative distributions of wage change are compared in figure 1. The upper left panel shows the histogram of wage changes in our Washington area survey. The histogram when our wage survey is dirtied as just described is shown in the upper right panel. And the lower right panel shows the histogram of wage changes calculated from the PSID of 1988, a year in which wage inflation was comparable to the average wage increase in our sample. The dirtied histogram shows a much fatter left tail and even more instances of negative wage change than the PSID, implying that an error-free distribution of wage changes from

13. Bound and Krueger (1991). 


\section{Figure 1. Distribution of Wage Changes for Job Stayers}

Distribution of wage changes in Washington area

Fraction

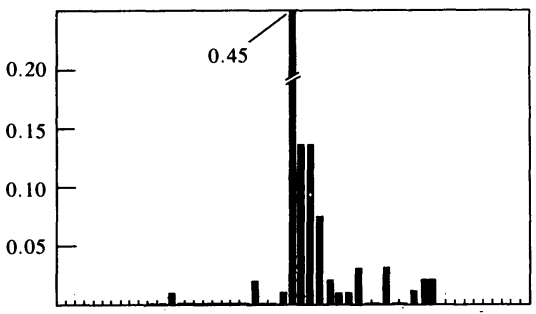

Response error added to Washington area survey: method $2^{\text {b }}$

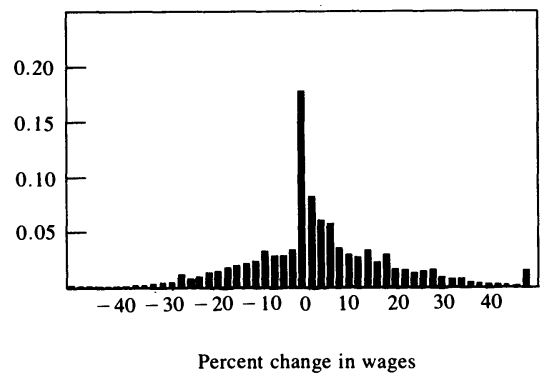

Response error added to Washington area survey: method $1^{\text {a }}$

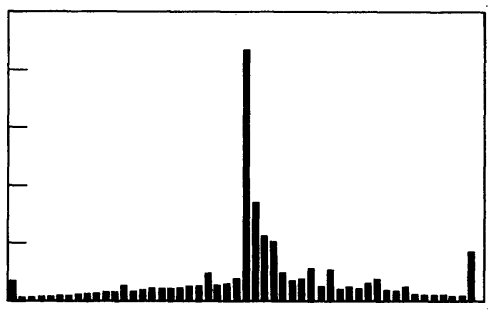

PSID distribution of changes in wages, 1988

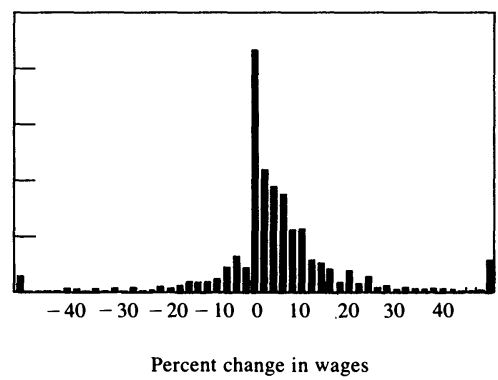

Source: Data for the upper left panel are from the authors' survey; for the lower right panel, from the Panel Study of Income Dynamics (PSID); and for the other panels, from the authors' calculations as described in text.

a. With correlation of correct responses in consecutive years of 1.0 , and standard deviation of response error of 0.167 .

b. With correlation of correct responses in consecutive years of 0.5 , and standard deviation of response error calculated so that standard deviation of distribution equals standard deviation of wage changes in the PSID.

the PSID would show an even smaller proportion of wage cuts than our survey.

Our conclusion that most negative wage changes in the PSID are due to measurement error is robust to various changes we made in generating the error term. We performed various checks. For example, since our data on wage changes probably also contain some measurement error, it should not be surprising that the standard deviation of our dirtied distribution is greater than that of the PSID. As a conservative alternative to the previous comparison, we assume a response error 
small enough to make the variation in our data plus this response error just conform to the PSID data for 1988. This yields approximately the same proportion of negative wage changes as that reported by Kahn. The lower left panel in figure 1 shows this alternative hypothetical distribution.

\section{Comparing Union Settlement Data with the PSID}

John Shea has examined the measurement errors for unionized workers in the PSID directly and reports his results in a discussion of the Card and Hyslop study. ${ }^{14}$ Shea matches individual PSID households to the provisions of particular union contracts by relating PSID information on individuals' industry, occupation, union affiliation, and county of residence to information from other sources about employers' locations and bargaining outcomes. For the period from 1981-82 through 1986-87, this procedure yields 379 observations for which Shea has contract data to compare with responses from employees in the PSID. He calculates that only 1.3 percent of his sample have received nominal wage cuts according to their contracts, while over the same period, 21.1 percent report wage levels in consecutive years of the PSID that, when subtracted, imply wage cuts.

As a further check on the PSID-based results, we compare the incidence of wage cuts calculated from the PSID data with the incidence of cuts in new union contracts discussed above. Kahn reports that, on the average, 11.8 percent of changes in nominal wages were negative for union workers in the PSID for the years 1976 to $1988 .{ }^{15}$ Given that only 3.5 percent of workers in large bargaining sessions took a pay cut in the first year of a new contract, this implies that a minimum of 70 percent of the negative wage changes from the PSID are spurious; recognizing that wage cuts are concentrated in the first year of multiyear contracts raises the proportion to 85 percent, on the assumption that any cuts occurred in the first year of two-year contracts. If the wages of workers involved in smaller settlements behave more like those in the nonunionized sector, the foregoing figures would overstate wage cuts if nonunion workers have a lower incidence of wage cuts than union workers. In fact, Kahn shows that in the PSID from 1976 to

14. Shea (1996).

15. Kahn (1995, table 2, p. 17). 
1988 , the incidence of negative wage changes for nonunionized workers is 20 percent lower than for unionized workers $(9.45$ percent as compared to 11.77 percent). ${ }^{16}$

\section{Comparing the PSID with Employers' Wage Reports}

We also have evidence about wage changes from employers' records to compare with the PSID data on wages of new hires. As a by-product of his study of the hiring and jobs of less-educated workers, Harry Holzer has obtained employer data on wages. He interviewed a random sample of employers in four cities: Atlanta, Detroit, Boston, and Los Angeles. All of these employers were asked about the work conditions of new hires, including the last person hired. Weighting the data by employer size, Holzer shows that one year after a vacancy had been filled, only 4.8 percent of new hires had taken a wage cut. ${ }^{17}$ These numbers are larger than those implied by our survey, and are also larger than the recent figures for union givebacks, but they are still quite small and, considering that they refer only to new hires, are not inconsistent with the other data. By contrast, the PSID data shows that 13.6 percent of new hires experience wage cuts in their first year on the job. ${ }^{18}$

\section{Other Ways to Cut Wage Costs}

Some may object that our attention to downward wage rigidity ignores other ways in which employers can reduce wage costs and so avoid the employment effects that we associate with this phenomenon. Firms could cut nonwage benefits, but we suspect that the scope for doing so is limited. Workers would object to cuts in benefits, just as they object to cuts in pay. Many companies have recently asked workers to pay a larger share of the cost of health insurance, but since health costs have, on average, been rising quite rapidly, in most cases such increases will only partly defray the companies' increasing costs for this benefit.

Firms could also hire new workers at wages below those paid to

16. Kahn (1995, table 2, p. 17).

17. Personal communication from Harry J. Holzer, Michigan State University, East Lansing, Mich., April 20, 1995, and Holzer (1996).

18. This is the fraction of job stayers with one to two years of tenure that reports lower wages in 1992 than in 1991. 
existing workers. While firms certainly have some freedom to adjust the wages of new hires, it is doubtful that this is important to our overall findings. First, the cost of new labor will not matter to a firm that is laying off workers. Second, a firm that is recovering from a negative shock that has resulted in a nominal constraint on its wage setting may well hire back laid-off workers, who will be paid their old wage. Finally, even a growing firm does not have complete freedom in how it sets its entry wages. Consider the controversy that arose in the early 1980s when a very few firms adopted "two-tier" salary systems that allowed newly hired workers to be paid less than those already on the job. The fact that this practice was newsworthy suggests that it is infrequent, and the worker resistance to the plans that was reported at that time suggests why.

More subtly, firms may avoid the customary wage increases associated with merit and seniority. In a firm that is maintaining its size or growing while undergoing normal turnover, such increases will lead to a reduction in labor costs. On the other hand, in a shrinking or stable firm with low turnover, the necessity of granting some merit increases, or increases with seniority or promotion, can add an upward drift to labor costs. Data from the PSID for average wage levels by age cohort, which are not sensitive to the reporting errors that we discuss above, permit us to estimate the size of normal wage gains of this type. Measured as the average annual wage change for a cohort of job stayers relative to the mean wage increase of all workers in the economy, these averaged 1.2 percent a year between 1970 and 1992. Freezing all the wage increases normally associated with merit, promotion, and seniority could provide savings in unit labor costs of about this amount.

We allow for all these effects in two ways. First, both the simulation model and a version of the time-series model presented below allow for a drift of individual wages relative to the economy mean wage, to capture the possibility that firms erode nominal wage constraints in the ways just discussed. Second, both models allow firms that are in distress to lower wages to desired levels.

\section{Summary}

To conclude, data on changes in wages and salaries that are relatively free of error strongly confirm the existence of downward nominal wage 
Table 3. Evidence on Nominal Wage and Salary Rigidity

\begin{tabular}{|c|c|c|}
\hline Source & Nature of data & Summary \\
\hline $\begin{array}{l}\text { Bureau of Labor } \\
\text { Statistics }\end{array}$ & $\begin{array}{l}\text { Changes in wages by } \\
\text { employers making general } \\
\text { wage changes, 1959-78 }\end{array}$ & $\begin{array}{l}\text { Negligible fractions of both } \\
\text { union and nonunion } \\
\text { employers making negative } \\
\text { changes }\end{array}$ \\
\hline $\begin{array}{l}\text { Authors' survey of } \\
\text { Washington area }\end{array}$ & $\begin{array}{l}\text { Phone survey of } \\
\text { respondents' wage changes } \\
\text { in previous year, } 1995\end{array}$ & $\begin{array}{l}1.7 \text { percent with negative } \\
\text { pay changes and no change } \\
\text { in job characteristics; } \\
\text { additional } 1 \text { percent with } \\
\text { changes in job } \\
\text { characteristics }\end{array}$ \\
\hline $\begin{array}{l}\text { Bureau of Labor } \\
\text { Statistics }\end{array}$ & $\begin{array}{l}\text { Contract settlements } \\
\text { involving more than } 1,000 \\
\text { workers }\end{array}$ & $\begin{array}{l}2.3 \text { percent of contracts } \\
\text { with negative changes in } \\
\text { first year, average 1970-94 }\end{array}$ \\
\hline Pierre Fortin & $\begin{array}{l}\text { Canadian labor contracts } \\
\text { without COLAs }\end{array}$ & $\begin{array}{l}0.25 \text { percent with wage } \\
\text { cuts during } 1986-88 ; 5.7 \\
\text { percent with cuts and } 47.2 \\
\text { percent with wage freezes } \\
\text { during } 1992-94\end{array}$ \\
\hline $\begin{array}{l}\text { Panel Study of Income } \\
\text { Dynamics }\end{array}$ & $\begin{array}{l}\text { Difference between } \\
\text { consecutive responses of } \\
\text { job stayers on wages and } \\
\text { salary }\end{array}$ & $\begin{array}{l}10.6 \text { percent of wage } \\
\text { earners and } 24.3 \text { percent of } \\
\text { salary earners with pay cuts }\end{array}$ \\
\hline $\begin{array}{l}\text { Harry Holzer four-city } \\
\text { study }\end{array}$ & $\begin{array}{l}\text { Changes in wages of new } \\
\text { employees reported by } \\
\text { firms hiring noncollege } \\
\text { graduates }\end{array}$ & $\begin{array}{l}4.84 \text { percent of new } \\
\text { employees with wage cuts }\end{array}$ \\
\hline $\begin{array}{l}\text { O'Brien, Hanes, and } \\
\text { others }\end{array}$ & Historical data & $\begin{array}{l}\text { Considerable wage rigidity } \\
\text { in prewar recessions }\end{array}$ \\
\hline
\end{tabular}

Source: Authors' summary of studies described in text.

rigidity. The results of different studies are summarized in table 3. All show an asymmetry of wage changes about the mean, and all but the PSID show that negative wage changes are quite rare. We show that reporting errors in the PSID cause wage changes calculated from that data to greatly exaggerate the actual frequency of wage declines. Indeed, reporting error in the PSID is sufficiently large to explain the difference between the distribution of wage changes constructed from the PSID and the other sources that we have described.

Despite the pervasive evidence, some model builders reject downward wage rigidity on the grounds that it implies money illusion. Some 
who might accept the idea that wage cuts are rare because they violate implicit contracts between firms and workers might, nonetheless, insist that the rigidity must apply to real rather than nominal wages. Having already provided direct evidence that downward rigidity is, in fact, widespread and applies to nominal wages, there is not much about wages that we can add in response. However, we would point to the existence of money illusion in another familiar context, the payment of dividends. Our computations using CRSP data show a pattern that strongly resembles that observed for nominal wage changes. Dividends are rarely cut, and the distribution of changes in nominal dividends is asymmetric and bunched at zero.

\section{Simulation Model}

In this section we present a formal model calibrated to the major stylized facts concerning wage change, job change, and estimates of the lowest sustainable rate of unemployment in the U.S. economy. This model rests on three pillars: monopolistic competition, large heterogeneous demand and supply shocks to different firms, and downward wage rigidity.

These three characteristics of the economy produce a nonlinear relation between long-run inflation and unemployment. Supply and demand shocks are heterogeneous: they affect firms that are monopolistically competitive. For a variety of reasons, workers share in the effects of firm-specific shocks. For example, a positive demand shock to a firm will result in a rise in the wages of the workers at that firm, and also in an increase in employment. These job shocks thus cause both job creation and job destruction, and dispersion in wage changes. With this heterogeneity, money wage rigidity will act as a constraint on the wage changes of some firms, even when wages in the economy as a whole are rising. The binding effect of downward wage rigidity raises real wages and decreases employment. The number of constrained firms and the effects of the constraint will be nonlinear with inflation.

Our simulation exercises are informed by empirical findings about these features of the U.S. economy. We have already documented from many sources the extent of downward rigidity in money wages. We now look briefly at the other two features. 
MONOPOLISTIC COMPETITION. Monopolistic competition is a pervasive feature of our economy. Very few prices are set in auction markets and virtually all firms have some discretion in determining the prices they charge. Robert Hall and Mark Bils both use the cyclical nature of the U.S. economy to infer the existence of extensive monopolistic competition from the observation that small changes in employment result in large changes in output. ${ }^{19}$ An elasticity of demand of -3.8 in our simulation model yields a labor share of 0.73 , as observed in the U.S. economy in 1994.

HETEROGENEITY OF WAGE AND EMPLOYMENT CHANGES. The third pillar of the model is heterogeneity in shocks to demand and supply. The U.S. economy displays considerable firm-level heterogeneity in wage and employment changes. The simulation model has sufficient firmlevel demand and supply shocks to generate these observations.

Jonathan Leonard and Steven Davis, John Haltiwanger, and Scott Schuh have documented that each year, on average, growing firms increase employment by an amount equal to about 11 percent of total employment, while shrinking firms contract employment by only slightly less. ${ }^{20}$ These numbers change a little over the course of the business cycle, but whatever the unemployment rate, gross job creation and gross job destruction are much larger than the corresponding net changes.

There is also ample evidence of significant heterogeneity in both the level and change of wages across individuals and firms. We have described a number of studies that attempt to measure the distribution of individuals' wage changes. ${ }^{21}$ However, the standard deviation of average wage changes for firms will be smaller than that for individuals. Using the BLS data for general wage increases for manufacturing establishments cited above, we computed what the standard deviation would be if the left half of the distribution were symmetrical with the right half. This approximates what the standard deviation would be in the absence of downward rigidity. For 1964-78, but excluding the oil shock years of the early 1970s, this procedure gives a median standard

19. Hall (1988); Bils (1987).

20. Leonard (1987); Davis, Haltiwanger, and Schuh (1996).

21. McLaughlin (1994) presents several estimates of the standard deviation of percentage real wage growth across individuals who stay on the same job. These estimates are corrected for measurement error, and none is less than 9.5 percentage points. 
deviation of 2.8 percentage points. This is probably lower than the variation in the change in the average wage across firms, since demand conditions may force firms to pay more or less for specific types of labor and this may affect average wages. Also, we compute that the standard deviation of negotiated first-year wage changes for the Canadian contract data described above ranges from 2 to 4 percentage points, depending on the year.

We believe the distribution of observed wages and wage changes reflects market forces and the desires of firms and workers. We further believe that if firms are forced to pay higher wages, they will hire less labor. ${ }^{22}$ The heterogeneity of wage changes may reflect changes in the demand and supply of idiosyncratic skills in small geographic or occupational markets. Alternatively, if wages are set to satisfy wage norms and such norms depend on profitability, or if wages reflect explicit or implicit bargaining, wage changes will depend on firm demand. Our simulation model allows for either interpretation.

\section{Deriving the Simulation Model}

The simulation model is presented in two parts. First, we describe the underlying representative firm model of monopolistic competition and wage setting. We then show how the simulation model is constructed from this model, by allowing a large number of simulated firms to face different supply and demand conditions and downward money wage rigidity. Without downward wage rigidity and heterogeneity, our simulated economy has unique equilibrium real wage and unemployment rates. The behavior of this economy can be summarized by the price setting and wage setting behavior of the monopolistically competitive firms.

PRICE DETERMINATION. Given monopolistically competitive firms, each with its own market niche, the demand for a firm's output $(D)$ will be

$$
D=\left[(M / \bar{p})(p / \bar{p})^{-\beta}\right] / n,
$$

22. See Dickens (1994) for a discussion of the theoretical and empirical evidence on whether labor demand responds to negotiated changes in wages; and Dickens (1986) for a discussion of the employment effects of wage changes in firms where bargaining is implicit or the threat of collective action forces them to pay higher wages. 
where $M$ is the money supply, $p$ is the price of the firm's output, $\bar{p}$ is the average price in the economy, and $n$ is the number of firms. The first factor, $M / \bar{p}$, for simplicity, represents aggregate demand. The second factor in equation $1,(p / \bar{p})^{-\beta}$, gives the downward slope to the demand for the firm's product. For a representative firm that is charging the average price, this term will be equal to one, since $p$ will be equal to $\bar{p}$. Nonetheless, the presence of this term affects the equilibrium output and pricing in the economy, since each firm takes $\bar{p}$ as given and sets prices to equate marginal cost and marginal revenue.

Each firm produces output $(Q)$ in proportion to labor input $(L)$ :

$$
Q=L \text {. }
$$

It is useful to normalize the labor force to equal one. So, letting the unemployment rate be $u$, output will be $1-u .^{23}$

Given the level of their wages, firms will choose prices to maximize profits. This maximization will determine individual firms' prices, $p$, and also the average level of all prices, $\bar{p}$. Once firms' prices are given, their demand is given according to equation 1, and so the level of output is also determined.

WAGE DETERMINATION. In the absence of any constraint against money wage cuts, the wage is assumed to result from an implicit or explicit bargain between the firm and its workers. We call the result of this bargain the notional wage, since it is the wage that would be set in the absence of any constraint due to nominal rigidities.

Consistent with the idea that the notional wage is the consequence of an implicit or explicit bargain between the firm and the workers, it is a weighted average of two factors. This is the generalized Nash solution: the surpluses of firms and workers, geometrically weighted according to bargaining power, are maximized with respect to the real wage. The firms' surplus consists of total revenues net of the wages paid to the workers and fixed costs. The workers' surplus is their wages net of their opportunity costs-their expected returns if they looked for jobs elsewhere.

23. With labor productivity $\left(G_{t}\right)$ changing, we assume that $Q=G_{t} L$. Also, with changes in productivity, we assume that fixed costs are proportional to full employment output, so they are proportional to $G_{t}$, and that $s$, the value of leisure, is also proportional to labor productivity. 
The bargained real notional wage, $\omega^{n}$, per efficiency unit is given by the formula ${ }^{24}$

$$
\omega^{n}=a[(p D-\bar{p} f) / \bar{p} L]+(1-a)[(1-u) \bar{w} / \bar{p}+u s],
$$

where $\bar{w}$ is the average nominal wage, $u$ is the unemployment rate, $a$ is an index of workers' bargaining power that takes values between zero and one, $s$ is the value of the workers' time while unemployed, and $f$ is the ratio of the fixed costs of the firm to the value of output at full employment. ${ }^{25}$ When worker bargaining power is equal to zero, wage setting becomes competitive, with the real wage equal to the opportunity cost of time.

\section{Analysis of the Representative Firm Model}

The equilibrium of the representative firm model occurs at the intersection of an aggregate demand equation resulting from pricing behavior, and an aggregate supply equation resulting from the wage setting model. Both of these relationships depend only on the real wage. The aggregate demand curve is the result of monopolistically competitive pricing. Each firm chooses its own price to maximize revenues net of payments to labor, taking the money wage and the aggregate price level as fixed. A firm whose demand curve has constant elasticity, as in

24. Such a wage equation can be easily derived as the generalized Nash solution when firms and workers bargain over wages but not employment. If workers receive a wage from the firm of $w^{n}$, the surplus per worker left to the firm in nominal terms will be

$$
S_{f}=p-\bar{p}(f / L)-w^{n},
$$

where $f$ represents the fixed costs of production. We assume that the capital of the firm is firm-specific, so it has no alternative use.

A worker's surplus for working for the firm is

$$
S_{w}=w^{n}-w_{o},
$$

where $w_{o}$ is the worker's opportunity cost. This value of the worker's alternative is, in turn, a weighted average. If the worker must seek employment elsewhere, with probability $u$ he or she will be unemployed and the value of staying at home will be denoted by $s$, which includes the unemployment benefit; and with probability $(1-u)$ that he or she will be employed and will, on average, receive the average wage in the economy. If $w^{n}$ is chosen to maximize the geometric mean of the firms' surplus and the workers' surplus-that is, to maximize $S_{f}^{1-a} S_{w^{a}}$ - the wage will be given by the bargaining equation (equation 3).

25 . We assume that $s$ and profits rise with productivity, and therefore, productivity affects the notional real wage in a multiplicative fashion. 
equation 1 , and with the production function of equation 2 , will set its nominal price, $p$, as a constant markup over the nominal unit labor cost. So the aggregate demand curve will be of the form

$$
\omega=(\beta-1) / \beta,
$$

where $\omega$ is the notional real wage.

Equation 4 conforms to our reading of the character of the real wage-it varies little with the cycle. Some have argued that the real wage is procyclic; others have argued that it is countercyclic. Equation 4 , which results from the constant elasticity of demand function, equation 2 , is embraced as a compromise between these two possible readings of the evidence. In figure 2, $A A$ represents equation 4 . It gives the response of prices, relative to wages, as a function of the level of demand (or employment). Because the real wage is constant, $A A$ is a horizontal line.

If the price equation, which is set taking wages as constant, is perceived as the aggregate demand equation, its counterpart, the aggregate supply curve, will be given by the wages that result from the wage determination process, which are set with constant price expectations. Thus the aggregate supply curve, which relates notional wages and unemployment, will come out of equation 3 . Noting that in equilibrium $p=\bar{p}, D / L=1, L=1-u$, and $\bar{w} / \bar{p}=(\beta-1) / \beta$ equation 3 will yield

$$
\omega^{n}=a[(1-f) /(1-u)]+(1-a)[(1-u)(\beta-1) / \beta+u s] .
$$

This is curve $S S$ in figure 2. It slopes upward because the value of workers' alternative uses of their time rises-as do profits-as unemployment falls. ${ }^{26}$ Along this curve, as employment rises the bargained real wage rises. As employment increases, unemployment declines, assuming constant labor supply.

\section{LSRU not NAIRU}

The equilibrium unemployment and real wage rates in this economy occur at the intersection of the $A A$ and the $S S$ curves. We call this level of unemployment the LSRU (lowest sustainable rate of unemployment).

26. As long as $s$, the value of leisure, is less than the real wage, $(\beta-1) / \beta$, $S S$ will slope upward. 
Figure 2. Reduced-Form Price and Wage Equations

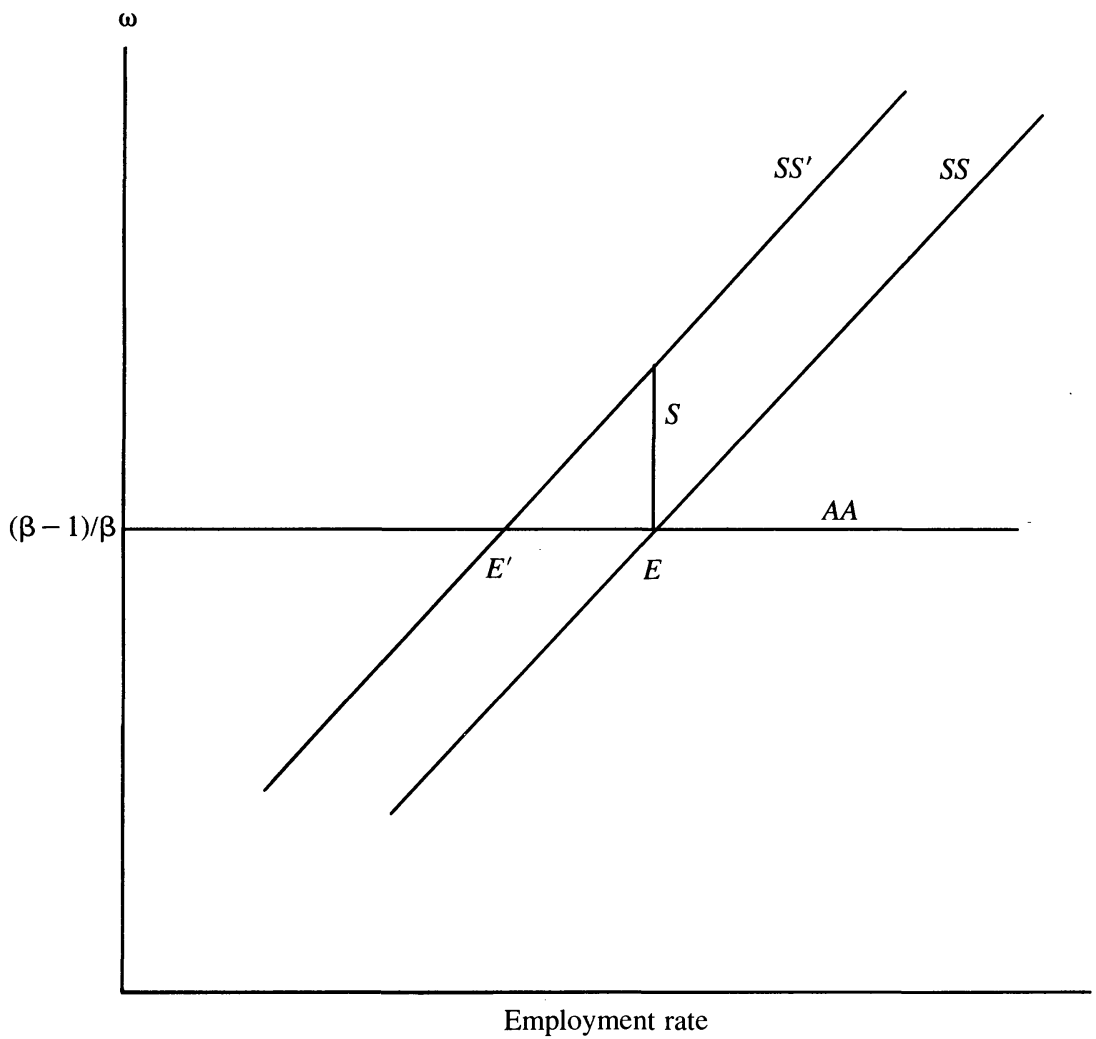

Source: Authors' model as described in text

In the absence of downward wage rigidity, the LSRU would constitute the NAIRU ("nonaccelerating inflation" rate of unemployment) of the model, the level of unemployment at which inflation remains constant. With downward wage rigidity, however, higher sustained rates of unemployment accompany very low rates of sustained inflation, and a unique NAIRU does not exist.

\section{Adding Heterogeneity and Wage Rigidity}

We now add firm-level heterogeneity and nominal wage rigidity to the model of the representative firm to obtain the simulation model. 
DEMAND AND SUPPLY HETEROGENEITY. Heterogeneity is introduced by the addition of a random term, $\epsilon$, to the demand for each individual firm. The demand equation, equation 1 , becomes

$$
D=(M / \bar{p})(p / \bar{p})^{-\beta} e^{\epsilon} / n .
$$

The expected value of $e^{\epsilon}$ is one because it represents the shocks specific to individual firms. We also assume that $\epsilon$ is serially correlated-following a simple $\mathrm{AR}(1)$ process. The innovations to $\epsilon$ are assumed to be normal with constant variance.

We also add heterogeneity to the wage bargains with a supplementary random term, $\eta$. The bargaining equation, equation 5 , becomes

$$
\begin{aligned}
\omega^{n}= & a[(p D-\bar{p} f) / \bar{p} L] \\
& +(1-a)[(1-u)(\beta-1) / \beta+u s]+\eta .
\end{aligned}
$$

The term $\eta$ is an $\operatorname{AR}(1)$ process with mean zero and constant variance normal innovations. It can be thought of as reflecting idiosyncratic variation in bargaining power or change in labor supply conditions.

Further realism is added by letting the bargained wage respond autoregressively to levels of current variables, such that

$$
\begin{aligned}
\omega^{n}= & (1-z) \omega_{-1}+z\{a[(p D-\bar{p} f) / \bar{p} L] \\
& +(1-a)[(1-u)(\beta-1) / \beta+u s]\}+\eta .
\end{aligned}
$$

MONEY WAGE RIGIDITY. It remains to describe in detail the nature of money wage rigidity in the simulation model. Complete money wage rigidity is too stark. Our survey and the interviews by Bewley and Brainard suggest that wage cuts are quite rare; nevertheless, sometimes they do occur. Bewley and Brainard suggest that firms are likely to make wage cuts after a second year of losses. The interviews of Kahneman, Knetsch, and Thaler show that most respondents would view reductions in money wages as fair if a firm was losing money. In this spirit, our simulation allows firms with two years of consecutive losses to cut wages to their notional level. When they do this, we also give those firms with negative $\epsilon$ an increase in that term that leaves $\epsilon$ partway between its former value and zero.

There are two possible interpretations of these features of the model. On the one hand, releasing the wage constraint could be viewed as an adjustment deemed fair by the existing workers after two years of 
losses. In this case, the increase in the firms' $\epsilon$ reflects reorganizing for greater efficiency as they cut wages. Alternatively, one might view the firms as going out of business. The workers in those firms find employment in new firms with no wage history to constrain wage setting. In this case, keeping $\epsilon$ negative would reflect the disadvantages experienced by new firms relative to established firms.

There are further reasons to relax the downward wage constraint. We discussed above how firms might try to find alternative ways to reduce labor costs if money wages cannot fall. This will only partly offset the effects of downward wage rigidity in unit labor costs, because either existing employees will resist changes, such as cuts in benefits, or the employer will be forced to adopt less efficient employment arrangements. The simulation allows for all these ways in which employers can circumvent downward wage rigidity, by assuming that constrained firms will be able to reduce their labor costs at the rate of 1 percent per year.

To summarize the treatment of downward wage rigidity: the nominal wage paid will be a fraction (0.99) of the previous money wage or the nominal notional wage, whichever is greater, except in the case of firms with two consecutive periods of losses. For those firms, the nominal wage will be the notional wage for a firm with the demand shift, $\epsilon$, decreased by a fraction of its value (if negative).

INTUITIVE WORKING OF THE SIMULATION MODEL. The effects of nominal wage rigidity in this model can also be seen in figure 2. Nominal wage rigidity shifts up the wage setting equation (supply equation) in figure 2 from $S S$ to $S S^{\prime}$. The amount of the shift depends on the rate of inflation. The resulting real wage and employment level can be found at the intersection of the aggregate demand curve and the shifted aggregate supply curve. With a horizontal $A A$ curve, the real wage is unchanged and all the effect of the shift is in employment. We describe below in greater detail the dynamics of this shift.

\section{Parameterization of Model and Simulation Results}

We now simulate the model to determine the effect on employment and output of targeting zero inflation. The procedure also provides evidence on the robustness of our results. Our simulation model has ten 
parameters. Three come from the demand equation, six from the wage setting equation, and one determines the behavior of firms that have two periods of negative profits. The parameters from the demand equation are the elasticity of demand $(\beta)$, the standard deviation $\left(\sigma_{\epsilon}\right)$ of the innovation in $\epsilon$, and the first-order autocorrelation of $\epsilon$. Parameters from the wage setting equation include the bargaining power of labor $(a)$, the level of fixed costs $(f)$, the value of time spent unemployed $(s)$, the degree of autoregression in the wage setting equation $(z)$, the standard deviation $\left(\sigma_{\eta}\right)$ of the innovation in $\eta$, and the first-order autocorrelation of $\eta$.

Prior knowledge does not allow us to specify with confidence the values of all these parameters. A commonly used alternative approach is to pick a number of characteristics of the economy equal to the number of parameters, and choose the parameter values so that the simulated values for those characteristics match the values for the actual economy. However, our simulation model is meant to characterize the behavior of the economy along many fewer dimensions than the number of parameters. So we simulate the performance of the economy for a large number of different combinations of parameter values, where each combination must match only three important characteristics of the economy: an equilibrium rate of unemployment at 3 percent inflation, the rate of job creation and destruction, and the standard deviation of firm wage changes. To do this, we divide the parameters into two groups: seven parameters chosen randomly, and three parameters that we use as instruments to hit our three targets. For those parameter combinations that permit the model to converge, we simulate the effect of reducing inflation from 3 percent to zero.

We choose the equilibrium rate of unemployment at 3 percent inflation as 5.8 percent, in accord with our perception that this is the median of existing natural rate estimates, and because the behavior of inflation over the last year and a half, when the unemployment rate has varied between 5.4 percent and 6 percent, suggests an equilibrium value in that range. We choose job creation and destruction to fit the observations of Leonard and Davis, Haltiwanger, and Schuh cited earlier, that about 11 percent of jobs are created, and slightly fewer destroyed, over the course of a year. ${ }^{27}$ Finally, we choose to make the standard deviation

27. The churning of employment between firms is a mechanism by which nominal 
of wage change equal to 2.8 percent, the number cited above from manufacturing data.

\section{Simulation Procedure}

Given the three characteristics of the real economy that we want our simulation to display, computational strategy determines how the ten parameters of our model are divided into two groups: three instruments and seven parameters to be chosen randomly. $s, \sigma_{\epsilon}$, and $\sigma_{\eta}$ are chosen as the instruments because we know that the equilibrium unemployment rate is substantially affected by $s$, while the amount of churning in firm size and the standard deviation of wage changes are most directly affected by $\sigma_{\epsilon}$ and $\sigma_{\eta}$, respectively.

The remaining parameters are chosen uniformly in their relevant ranges. The two autocorrelation parameters are chosen between 0 and 1. The weight on the share of profits is chosen between 0 and 1 . The elasticity of demand is chosen between 2 and 6, comfortably encompassing the value of 3.8 which is consistent with labor's share in the U.S. economy. Fixed costs (times $n$ ) are chosen between 0.0 and 0.3 , so as to keep total fixed costs below capital's share, which is less than 0.3 . The extent of reversion of the demand shock for reorganizing firms (those with two periods of negative profits) is chosen between 0 and 1 . Finally, the bargaining power of labor $(a)$ is allowed to take any value between 0 and 1 .

For each attempted simulation, the seven random parameter values are chosen first. Then the program, through an iterative process, moves the instruments so as to match the three simulated characteristics to their target values-unemployment of 5.8 percent, a job creation rate of 0.11 , and a standard deviation of wage changes of 2.8 percent. The value of time while unemployed $(s)$ is restricted to exceed 0 in this exercise. In over 80 percent of the cases, it is impossible to hit the targets given the values of the randomly chosen parameters and the restriction on $s .{ }^{28}$ When the program is able to find values for the three

rigidity is overcome in the economy, and by embodying this feature we capture this mechanism in the simulation. Constrained firms will tend to shrink, and workers who lose employment at high wage constrained firms may find reemployment at low wage unconstrained firms.

28. We checked a number of these cases to be sure that the failure to find acceptable parameter values for so many cases is due to their nonexistence and does not represent 
instrumental parameters that allow the simulation to hit the three targets, it then simulates the effect of reducing the inflation rate from 3 percent to zero and records the results. The process is repeated to obtain a reasonable number of simulation trials.

\section{Long-Run Simulation Results}

With 432 successful runs of the simulation, the median increase in the equilibrium unemployment rate associated with operating with zero rather than 3 percent inflation is 2.1 percentage points. The minimum value obtained is 0.6 percentage points. The tenth percentile of the distribution of unemployment changes is 1 percentage point, and the ninetieth percentile is 5.7 percentage points. The range containing 90 percent of the simulated values runs from 0.8 percentage points to 8.5 percentage points.

To examine the long-run relation between inflation and unemployment, we choose benchmark parameters to look at a typical case, and then adjust them slightly to hit our three targets. We choose the elasticity of demand $(\beta)$ as 3.8 to yield a labor share of 0.73 , and we set the bargaining power of labor $(a)$ at 0.2 , the fraction of fixed costs $(f)$ at 0.15 , and the value of time spent unemployed $(s)$ at 0.38 . We set the standard deviation of demand shocks at 0.25 and the standard deviation of shocks to the wage equation at 0.02 . We set the autocorrelation coefficients for the two error processes to 0.75 and the smoothing coefficient for wage bargaining ( $z$ ) to 0.75 . Finally, we reset the $\epsilon$ of firms with two periods of negative profits to half its former value (when, as in the great majority of cases, it was negative).

The long-run Phillips curve corresponding to these parameter values is pictured in figure 3. The LSRU is, by assumption, 5.8 percent. At 3 percent inflation, unemployment is 5.9 percent, only 0.1 point above the LSRU. Equilibrium unemployment increases at an accelerating rate as inflation is held below 3 percent. At 2 percent inflation, it rises to 6.1 percent; at 1 percent, to 6.5 percent; and at zero inflation to 7.6

a failure of our search algorithm. Doing a grid search by hand, we were unable to find values of our instrumental parameters that allowed our simulation to hit the three calibration targets. The failure is due to the wide range of values that we allow the randomly chosen parameters to take. In experiments where the ranges are sharply restricted, the search algorithm is able to calibrate the simulation in the majority of cases. 
Figure 3. Long-Run Phillips Curve, Simulation Model

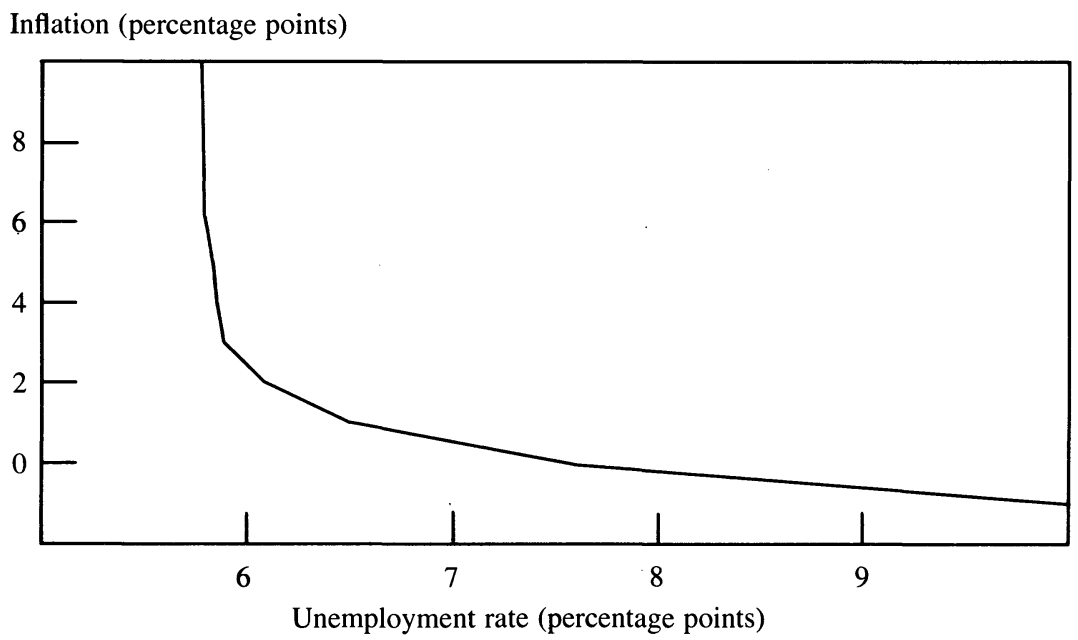

Source: Authors' calculations from simulation model.

percent. Deflation is yet worse: with 1 percent deflation, the equilibrium unemployment rate rises to 10.0 percent.

A HEURISTIC EXPLANATION. The higher unemployment associated with zero inflation should be no surprise. Define $S$ as the difference between average actual and average notional wages, divided by the expected price level. The increase in $S$ associated with going from 3 percent to zero inflation acts like a permanent real cost shock, which producers will try to pass on to their customers. Notional real wages must fall sufficiently to offset this real cost shock. And lower notional real wages require higher unemployment. Any attempt-for example, through stabilization policy-to maintain employment at its former level but with the cost shock equal to $S$, would require prices higher than expected prices. This disequilibrium expectation only goes away as higher inflation takes $S$ back to its initial level.

Figure 2 helps in understanding this change in the equilibrium level of unemployment. The wage setting curve, $S S$, and the actual wage curve at zero inflation, $S S^{\prime}$, will differ by $S$. This difference will be the consequence of downward wage rigidity. Since the $A A$ curve is flat, the increase in unemployment- the shift from $E$ to $E^{\prime}$ - will be the product of $S$ and the slope of the wage setting equation. For example, in the 
benchmark case, $S$ increases from almost zero to 1 percent of wages as long-term inflation falls from 3 percent to zero. Calculation shows that with the benchmark parameters, the slope of the wage setting equation is about two, and therefore the change in the unemployment rate is, likewise, approximately 2 percentage points.

The argument why the slope of the wage setting equation with respect to the unemployment rate will be the appropriate multiplier of the increase in wages due to downward rigidity follows in three steps. First, each level of steady-state inflation is associated with a given constant value of $S$. Second, for any such value of $S$, there will be only one employment level with constant inflation. This is so because in each period with an expected price level $p^{\mathrm{e}}$, the average nominal wage will be set equal to $p^{\mathrm{e}}\left(\omega^{n}+S\right)$, where $\omega^{n}$ is the notional wage. The price will be set as the markup over this actual wage, $[\beta /(\beta-1)] p^{e}\left(\omega^{n}+\right.$ $S)$. If $\left(\omega^{n}+S\right)$ exceeds $(\beta-1) / \beta$, actual prices will exceed expected prices and there will be accelerating inflation. Similarly, if $\left(\omega^{n}+S\right)$ is less than $(\beta-1) / \beta, p$ will be less than $p^{e}$ and there will be decelerating inflation. As a result, the only point in the diagram where there is a constant inflation rate of zero, and where the value of $S$ corresponds to zero inflation, will be $E^{\prime}$. Third, if a constant level of zero inflation is to be maintained, as in the diagram, the unemployment rate must exceed the LSRU (which is unemployment at $E$ ) by $S$ times the slope of $S S$.

The slope of this wage settlement equation can be estimated fairly robustly. It is the inverse slope of the Phillips curve with respect to the unemployment rate. In our estimations reported below, it is very close to two.

PROPORTION OF FIRMS CONSTRAINED. The nonlinear response of unemployment to inflation is mirrored in the fraction of constrained firms, as shown in table 4 . As inflation falls from 3 percent to zero, the fraction of constrained firms rises from 5 percent to 33 percent. The fraction of firms making readjustments as a result of two periods of negative profits rises as inflation falls, but this change is small. This behavior occurs because, following Leonard and Davis, Haltiwanger, and Schuh, we set the rate of job creation and destruction very high, even at the LSRU. This means that a considerable fraction of businesses will be making readjustments even at high and moderate rates of inflation, and their number will not increase much as inflation falls and unemployment rises. 
Table 4. Unemployment and Firms Constrained and Reorganizing, by Rate of Inflation

Percent

\begin{tabular}{cccc}
\hline Inflation & Unemployment & $\begin{array}{c}\text { Firms constrained } \\
\text { in wage setting }\end{array}$ & $\begin{array}{c}\text { Firms } \\
\text { reorganizing }\end{array}$ \\
\hline 10 & 5.8 & 0 & 3.1 \\
7 & 5.8 & 0.2 & 3.1 \\
5 & 5.8 & 1 & 3.2 \\
4 & 5.8 & 2 & 3.2 \\
3 & 5.9 & 5 & 3.3 \\
2 & 6.1 & 10 & 3.4 \\
1 & 6.5 & 19 & 3.6 \\
0 & 7.6 & 33 & 3.9 \\
-1 & 10.0 & 53 & 4.3 \\
\hline
\end{tabular}

Source: Authors' calculations from simulation model.

\section{Checks for Robustness}

The simulation is most sensitive to three parameters: the value of time unemployed $(s)$, the bargaining power of labor $(a)$, and the standard deviation of the innovation to the wage bargain $\left(\sigma_{\epsilon}\right)$. Figure 4 plots the simulated change in the equilibrium unemployment rate between 3 percent and zero inflation for different values of $s$. This parameter is chosen to obtain an unemployment rate of 5.8 percent at a simulated inflation rate of 3 percent, given the values of the seven randomly chosen parameters. When those randomly chosen parameters dictate a value of $s$ that is close to the average real wage, employment becomes very sensitive to small changes in the wage, exacerbating the effect of nominal rigidity. For values of $s$ below 0.45 , there are no simulations where the increase in unemployment is greater than 5 percentage points.

When the bargaining power of labor $(a)$ is small, demand shocks have little or no effect on wages. To reach the target standard deviation of wage changes, the simulation increases the variation of the innovation to the bargaining equation $\left(\sigma_{\eta}\right)$. The responsiveness of unemployment to a zero inflation target depends on the nature of the variation in wages. Figure 5 shows that as the bargaining power of labor increases, the effects of zero inflation decline considerably.

The other parameters have much smaller effects on the change in the unemployment rate. Higher values of the autocorrelation coefficient in the wage determination process $(z)$ and the error process in the wage bargaining equation are associated with increases in the change in the 
Figure 4. Simulated Changes in Unemployment vs. the Value of Leisure $(s)^{\mathrm{a}}$

Change in unemployment (percentage points)

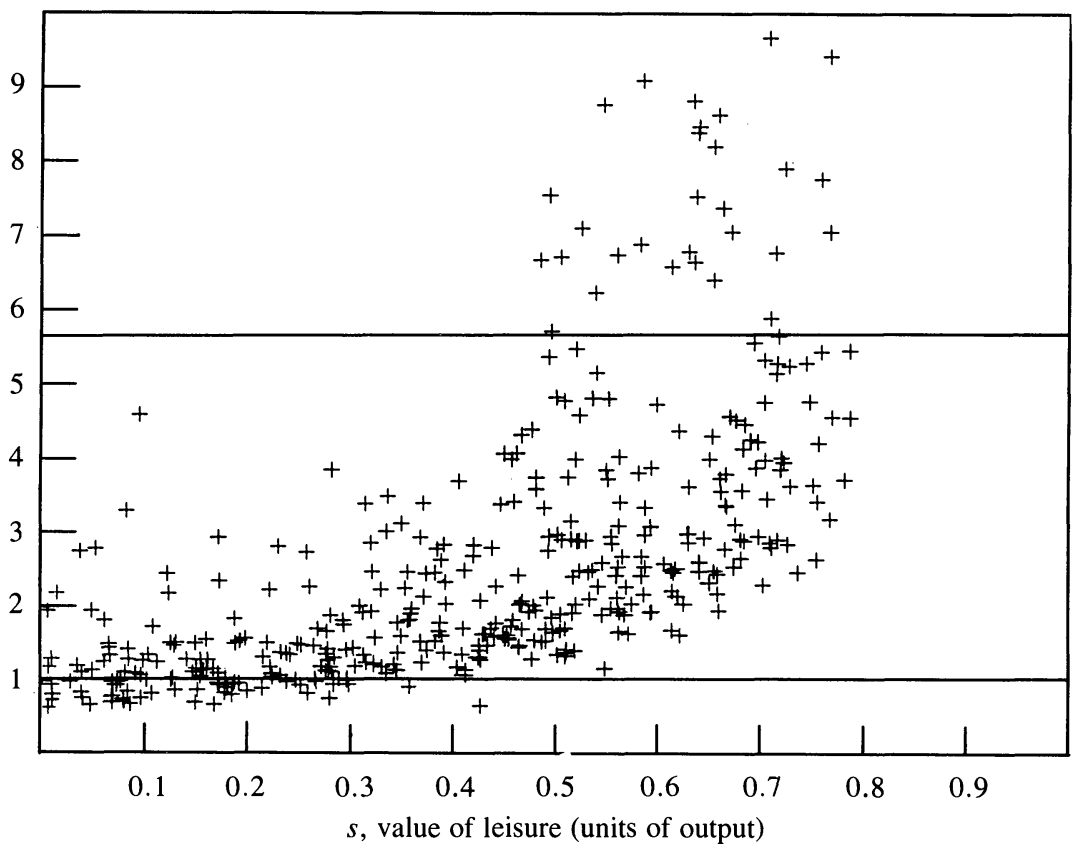

Source: Authors' simulations.

a. Calculating the change in unemployment associated with operating at zero rather than 3 percent inflation.

unemployment rate of about 1.5 percentage points over their ranges. Other parameters are associated with still smaller differences.

In a very large fraction of the cases in which we are unable to calibrate the simulation, the reason is that the only value of time spent unemployed $(s)$ that would yield an unemployment rate of 5.8 percent was negative. We experiment with allowing a lower bound of -1 for this parameter, instead of 0 . When we do this the median change in the unemployment rate declines to 1.3 percentage points and the minimum value observed in 722 trials is 0.3 percentage points. The fifth percentile of the distribution is 0.4 percentage points.

Finally, the simulation is predictably sensitive to the assumption about the conditions under which firms are allowed to reduce their wages. We conduct a number of runs in which we allow firms to escape the constraint of nominal wage rigidity when profits have been negative 
Figure 5. Simulated Changes in Unemployment vs. Workers' Bargaining Power $(a)^{\mathrm{a}}$

Change in unemployment (percentage points)

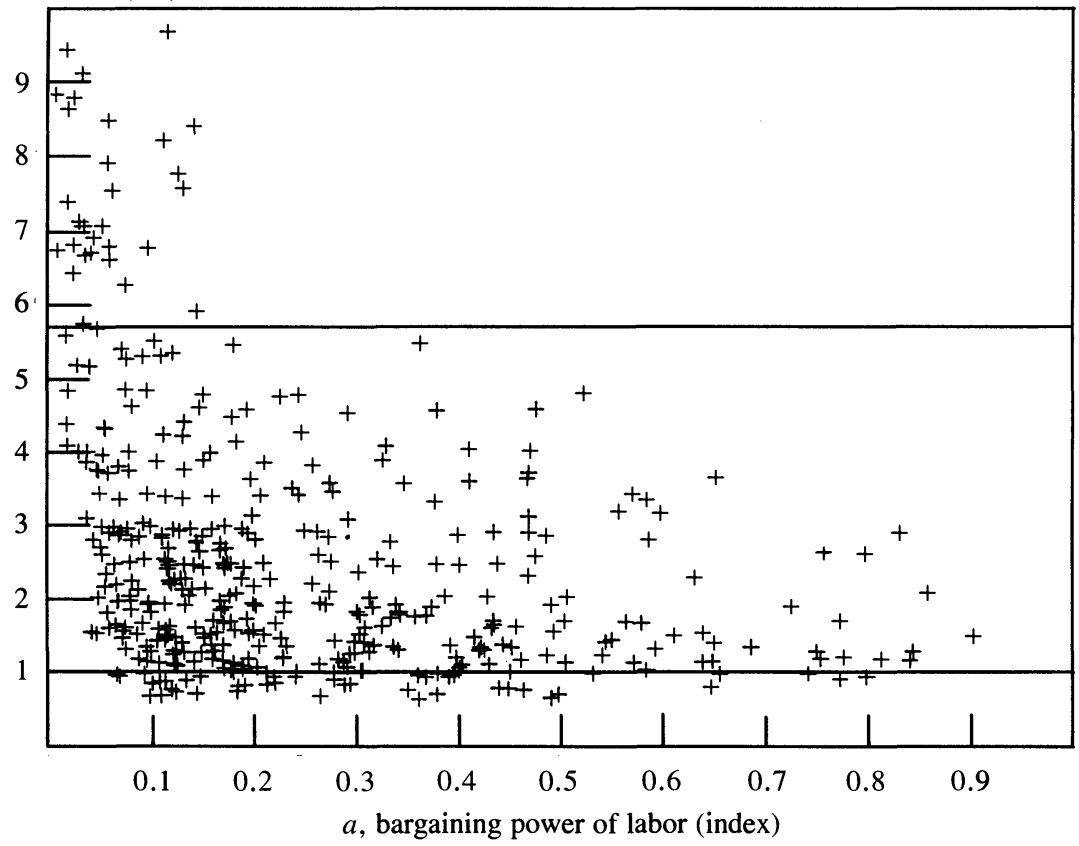

Source: Authors' simulations.

a. Calculating the change in unemployment associated with operating at zero rather than 3 percent inflation.

for only one period, rather than two. When we do this for 289 simulation runs, there are a couple in which there is no measurable change in the equilibrium unemployment rate between 3 percent and zero inflation. The median change drops to 1.5 percentage points and the fifth percentile of the distribution is 0.2 percentage points.

\section{A Model for Estimation}

A model derived as an approximation to the simulation model yields an equation for inflation that can be estimated by nonlinear least squares. We add a term reflecting the effects of downward wage rigidities to the standard accelerationist Phillips curve (for example, as 
estimated by Robert Gordon). ${ }^{29}$ We denote this additional term $S_{t}$ because it is the shift in expected unit labor costs arising from downward wage rigidity. $S_{t}$ is defined as the gap between the average level of expected real actual and notional wages deflated by labor productivity $\left(G_{t}\right): S_{t}=\left(\bar{w}_{t}-\bar{w}_{t}^{n}\right) / p_{t}^{e} G_{t}$. The shift in unit labor costs because of downward wage rigidity should have the same effect on the Phillips curve as a change in unit labor costs for any other reason. As a consequence, $S$, enters the price Phillips curve linearly, as if it were a shift to the wage setting equation.

$S_{t}$ is determined by the behavior of its two components, the actual wage and the notional wage. The notional wage is determined by the wage setting equation, and will therefore depend on the level of unemployment. Because of downward wage rigidity, the actual wage of each firm this period is either the notional wage of this period or the actual wage of last period, whichever is greater. Thus actual wages depend on past wages, and hence $S_{t}$ depends on its own past value. We derive how $S_{t}$ enters the Phillips curve, and then explain the recursion in which $S_{t}$ is a function of $S_{t-1}$ and other variables. (Further details of these derivations are provided in appendix A.)

\section{The Augmented Phillips Curve}

In this intermediate model, $S$, enters as an additional linear variable in an otherwise conventional Phillips curve. To understand why this is so, it is useful to consider how a price Phillips curve can be derived from a wage setting equation. In the absence of nominal wage rigidities, expected real wages for this period will be the real notional wage. Thus the nominal wage will be the product of the expected price level and the notional real wage:

$$
w_{t}=p_{t}^{e} \omega_{t}^{n} .
$$

Today's price will be the product of the markup factor $(m)$ and unit labor cost, so that

$$
p_{t}=m p_{t}^{e} \omega_{t}^{n} / G_{t} .
$$

The usual Phillips curve is derived by taking the natural log of equation

29. Gordon (1994). 
7 , subtracting the natural $\log$ of $p_{t-1}$ from both sides, and expressing the natural $\log$ of $\omega_{t}^{n}$ in terms of its arguments. The equation that we estimate is derived by exactly the same process. But because of nominal wage rigidity, the average wage will be higher than $p_{t}^{e} \omega_{t}^{n}$ by $p_{t}^{e} G_{t} S_{t}$, and thus, with the markup, the price level will be higher by $m p_{t}^{e} S_{t}$. Thus with nominal rigidity, the current wage and the current price for a representative firm are given by the modified equations

$$
w_{t}=p_{t}^{e}\left(1+S_{t} G_{t} / \omega_{t}^{n}\right) \omega_{t}^{n}
$$

and

$$
p_{t}=m p_{t}^{e}\left(1+S_{t} G_{t} / \omega_{t}^{n}\right) \omega_{t}^{n} / G_{t},
$$

respectively. The estimation equation is obtained by taking the natural $\log$ of each side of equation $7 \mathrm{a}$ and subtracting the natural $\log$ of $p_{t-1}$ from both sides of the equation. Because the difference between the notional wage and the actual wage will be small in equilibrium, $\omega_{t}^{n} / G_{t}$ can be approximated as $(\beta-1) / \beta$ and therefore, the natural log of $\left(1+S_{t} G_{t} / \omega_{t}^{n}\right)$ is approximately equal to $[\beta /(\beta-1)] S_{t}$. We also approximate the wage setting equation (equation 5 ) as a loglinear function of unemployment. This yields as the equation to be estimated

$$
\pi_{t}=\pi_{t}^{e}+c-a u_{t}+\frac{\beta}{\beta-1} S_{t},
$$

where $\pi_{t}$ is the rate of price inflation and $\pi_{t}^{e}$ is the expected rate of price inflation.

Equation 8 is the usual accelerationist Phillips curve with the addition of the term $[\beta /(\beta-1)] S_{t}$. It remains to determine a recursion equation for $S_{t}$, which is otherwise unknown, so that it can be jointly estimated with the other terms in this augmented Phillips curve.

\section{The Recursive Nature of $S_{t}$}

In the recursion equation, $S_{t}$ depends on its past values and other variables. To begin the derivation, recall the definition $S_{t}=\left(\bar{w}_{t}-\right.$ $\left.\bar{w}_{t}^{n}\right) / p_{t}^{e} G_{t}$. Because of downward wage inflexibility, the wage of each firm will be the maximum of the notional wage and the nominal wage 
of the previous period. Thus $S_{t}$ can be inferred from the joint distribution of $w_{t-1}$ and $w_{t}^{n}$.

We assume that for each firm, $w_{t-1}$ and $w_{t}^{n}$ have a bivariate normal distribution, and that the means of this distribution vary over time but the standard deviations and the covariance, when normalized by the expected price level $\left(p_{t}^{e}\right)$ and by trend productivity $\left(G_{t}\right)$, are constant. This makes sense as an approximation, since in the long run nominal wages will be proportional to both productivity and prices. We choose the expected rather than the actual price for the normalization of the standard deviation, since $S_{t}$ is the difference between notional and actual wages, which are set on the basis of expected rather than actual prices.

Given that for each firm $w_{t}$ is simply the maximum of $w_{t-1}$ and $w_{t}^{n}$, the difference between $\bar{w}_{t}$ and $w_{t}^{n}$ will equal the expected value of $\left(w_{t-1}-w_{t}^{n}\right)$ when $\left(w_{t-1}-w_{t}^{n}\right)$ is greater than zero, multiplied by the probability that $\left(w_{t-1}-w_{t}^{n}\right)$ is greater than zero. Define the new variable, $v_{t}=\left[\bar{w}_{t-1}-\bar{w}_{t}^{n}\right] / p_{t}^{e} G_{t}$. If $w_{t-1}$ and $w_{t}^{n}$ have a bivariate normal distribution, their difference will have a normal distribution, and the expected value of the truncated normal will be

$$
\begin{aligned}
S_{t} & =\frac{E\left(\left(w_{t-1}-w_{t}^{n}\right) \mid\left(w_{t-1}-w_{t}^{n}\right)>0\right) \operatorname{Pr}\left(w_{t-1}-w_{t}^{n}>0\right)}{p_{t}^{e} G_{t}} \\
& =\sigma_{0} \phi\left(v_{t} / \sigma_{0}\right)+\Phi\left(v_{t} / \sigma_{0}\right) v_{t},
\end{aligned}
$$

where $\phi$ and $\Phi$ are, respectively, the standard normal density function and the cumulative normal distribution function (see appendix $\mathrm{A}$ for the proof).

Equation 9 expresses $S_{t}$ as a nonlinear function of $v_{t}$. To obtain the recursion for our estimation, one needs to express $v_{t}$ as a function of $S_{t-1}$ and current and past values of other variables. This comes from the decomposition of $v_{t}$ as the difference of two components,

$$
v_{t}=\frac{\bar{w}_{t-1}-\bar{w}_{t-1}^{n}}{p_{t}^{e} G_{t}}-\frac{\bar{w}_{t}^{n}-\bar{w}_{t-1}^{n}}{p_{t}^{e} G_{t}} .
$$

The first term of the decomposition is a multiple of $S_{t-1}: p_{t-1}^{e} G_{t-1} /$ $p_{t}^{e} G_{t}$. The second term of the decomposition is the same multiple of the product: $\left[\bar{w}_{t-1}^{n} / G_{t-1} p_{t-1}^{e}\right]\left[\bar{w}_{t}^{n}-\bar{w}_{t-1}^{n} / \bar{w}_{t-1}^{n}\right]$. The first factor of this 
product is approximated from the markup equation as $(\beta-1) / \beta$; the second factor, the percentage change in the notional wage, $p_{t}^{e} \omega_{t}^{n}$, is approximated as $\pi_{t}^{e e}+g_{t}-a\left(u_{t}-u_{t-1}\right)$, where $\pi_{t}^{e e}$ is the rate of change of price expectations and $g_{t}$ is the growth of productivity. Hence the recursion formula for $v_{t}$ in terms of $S_{t-1}$ is

$$
v_{t}=\frac{S_{t-1}-[(\beta-1) / \beta]\left[\pi_{t}^{e e}+g_{t}-a\left(u_{t}-u_{t-1}\right)\right]}{1+\pi_{t}^{e e}+g_{t}}
$$

(see appendix A for greater detail). In terms of expected and actual price inflation, $\pi_{t}^{e e}$ is given by

$$
\pi_{t}^{e e} \cong \ln p_{t}^{e}-\ln p_{t-1}^{e} \cong \pi_{t}^{e}+\pi_{t-1}-\pi_{t-1}^{e},
$$

where

$$
\pi_{t}^{e}=\alpha \pi_{t-1}+(1-\alpha) \pi_{t-2} .
$$

The estimation equation must also take account of the feature of the simulation model whereby firms under extreme duress are allowed to reduce their wages. We introduce this feature into the equation by assuming that $v_{t}$ will decline if there is a drop in the profit share of GDP, denoted $r$. This yields the final element of the equation that we estimate:

$$
\begin{aligned}
v_{t}= & \frac{S_{t-1}-[(\beta-1) / \beta]\left[\pi_{t}^{e e}+g_{t}-a\left(u_{t}-u_{t-1}\right)\right]}{1+\pi_{t}^{e e}+g_{t}} \\
& +d\left(r_{t}-r_{t-1}\right),
\end{aligned}
$$

where $r_{t}$ is the share of profits in GDP.

We estimate the augmented Phillips curve of equation 8 jointly with the formula for $S_{t}$ in terms of $v_{t}$ (equation 9), $v_{t}$ in terms of $S_{t-1}$ (equation 14), and the formation of price expectations (equations 12 and 13). We estimate the five parameters: $c$ and $a$ in equation $14, \sigma_{0}$ in equation 9 , $d$ in equation 14 , and $\alpha$ in equation 13. The parameter $\beta$ is unidentified and is assumed to equal 3.8-as in the benchmark simulation: Changing this value does not affect the impact of nominal constraints.

\section{Explanation of the Recursion Formula for $\mathrm{S}_{\mathrm{t}}$}

First, it is important to understand why $S_{t}$ should depend on $v_{t} ; v_{t}$ represents the gap between the average wage of last period and the average notional wage of this period. 
To gain an intuitive appreciation for these equations, it is useful to see how $S_{t}$ responds to different values of $v_{t}$ according to equation 9 . Consider first two extremes. When almost all firms are constrained, $v_{t}$ will be very large. In this case, the first term in equation 9 will be zero. The second term will be equal to $v_{t}$. From the definitions of $S_{t}$ and $v_{t}$, wages in this period will be exactly equal to wages last period, which is what should happen if all firms are constrained. On the other hand, if $v_{t}$ is very negative, as it would be with very high inflation, no firms will be constrained; and there will be no difference between notional and actual wages. This corresponds to a value of $S_{t}$ that is close to zero. Both the first term and the last term of equation 9 will be zero. By the definition of $S_{t}$, the actual wage will be equal to the notional wage, as should be the case without binding wage constraints. Between these two extremes, the second term of equation 9 determines the extent to which formerly constrained firms continue to be constrained, while the first term represents the effects on firms that did not have binding constraints last period, but whose wage constraints have become binding in this period. At low levels of inflation and productivity growth, this term will cause $S_{t}$ to grow.

It remains to explain the arguments and the form of equation 11 , for $v_{t}$. Consider that $v_{t}$ and $S_{t-1}$ differ in their numerators by the difference $\bar{w}_{t}^{n}-\bar{w}_{t-1}^{n}$, while the denominators differ by a factor $p_{t}^{e} \mathrm{G}_{t} / p_{t-1}^{e} G_{t-1}$. It should therefore be no surprise that equation 11 , which expresses $v_{t}$ as a function of $S_{t-1}$, should have as arguments the growth of inflationary expectations, the growth of productivity, and the change in the unemployment rate, which are the major determinants of the change in the notional wage.

The economic reasons why each of these three arguments will affect $S_{t}$ should be clear. Productivity growth and inflation will raise the notional wage and therefore narrow the gap between actual and notional wages. A rise in the unemployment rate, on the other hand, will reduce the notional wage and therefore will increase the gap between actual and notional wages. The exact form of the relation between $v_{t}$ and $S_{t-1}$ as a function of these change variables (equation 11) reflects the weights that must be attached to these change variables as a result of the form of the difference between $v_{t}$ and $S_{t-1}$.

In sum, equation 9 modulates the change in $S_{t}$ according to the number of firms that face wage constraints. Operating jointly, equations 
9 and 14 give the appropriate weights to inflation, productivity growth, and changes in unemployment in changing $S_{t}$. By raising the notional wage, inflation and productivity growth erode the gap between the actual and the notional wage, whereas increases in unemployment decrease the notional wage, and therefore increase that gap. This behavior should be kept in mind in our examination of prices and the predictions of $S_{t}$ in the Great Depression.

\section{Time-Series Estimation}

We fit our model to annual time-series data using the log change in the GDP deflator to measure inflation. We use the aggregate unemployment rate because we want to predict historical periods out of sample, for which only the aggregate rate is available. And we use the ratio of corporate profits to GDP, with the 1954-84 trend removed, to measure the change in the profit share. For comparison, we also fit a standard natural rate model to the same data by omitting $S_{t}$ from the regression. The first two columns of table 5 give the regression estimates for the postwar years 1954-95: equation 5-1 is the natural rate model and equation $5-2$ is our downward rigidity model. ${ }^{30}$

The estimates in equation 5-1 are unremarkable and the implied minimum sustainable rate of unemployment, the LSRU here, is 5.9 percent, which is typical of natural rate estimates for such models. Equation 5-2 fits the data slightly better. Inflation enters with a shorter lag than in the standard model and the implied LSRU is 5.2 percent. In the parameters estimated in forming $S_{t}$, the standard deviation of the desired change in real productivity adjusted wages is 2.9 percent, which is very near the value that we estimate for the distribution of general manufacturing wage changes, discussed above. The profits term has the expected sign and a magnitude that would make its effect noticeable in providing some relief from wage constraints. We are not surprised that the estimate has a high standard error, since we did not expect, and do not find, much variation in $S_{t}$ during the postwar years. This lack of variation is apparent from the bottom panel of figure 6 , and is the reason

30. Our treatment of productivity growth, oil shocks, and wage and price controls is explained in appendix A. 
Table 5. Regression Estimates of Phillips Curve Models of Inflationa

\begin{tabular}{|c|c|c|c|c|c|}
\hline \multirow[b]{3}{*}{$\begin{array}{l}\text { Independent } \\
\text { variable }\end{array}$} & \multicolumn{5}{|c|}{ Period of estimation and model } \\
\hline & \multicolumn{2}{|c|}{$1954-95$} & \multirow{2}{*}{$\begin{array}{c}1929-42 \\
\begin{array}{c}\text { Downward } \\
\text { rigidity } \\
(5-3)\end{array}\end{array}$} & \multicolumn{2}{|c|}{ Combined sample } \\
\hline & $\begin{array}{c}\text { Standard } \\
(5-1)\end{array}$ & $\begin{array}{l}\text { Downward } \\
\text { rigidity } \\
(5-2)\end{array}$ & & $\begin{array}{c}\text { Standard } \\
(5-4)\end{array}$ & $\begin{array}{c}\text { Downward } \\
\text { rigidity } \\
(5-5)\end{array}$ \\
\hline Constant & $\begin{array}{c}0.031 \\
(0.008)\end{array}$ & $\begin{array}{c}0.026 \\
(0.010)\end{array}$ & $\begin{array}{c}0.027 \\
(0.018)\end{array}$ & $\begin{array}{c}-0.003 \\
(0.008)\end{array}$ & $\begin{array}{c}0.033 \\
(0.004)\end{array}$ \\
\hline Inflation $t-1$ & $\begin{array}{c}0.68 \\
(0.16)\end{array}$ & $\begin{array}{c}0.83 \\
(0.22)\end{array}$ & $\begin{array}{c}1.16 \\
(0.16)\end{array}$ & $\begin{array}{c}1.06 \\
(0.14)\end{array}$ & $\begin{array}{c}0.97 \\
(0.11)\end{array}$ \\
\hline Inflation $t-2$ & 0.32 & 0.17 & -0.16 & -0.06 & 0.03 \\
\hline Unemployment & $\begin{array}{c}-0.52 \\
(0.13)\end{array}$ & $\begin{array}{c}-0.50 \\
(0.13)\end{array}$ & $\begin{array}{r}-0.59 \\
(0.24)\end{array}$ & $\begin{array}{c}0.04 \\
(0.08)\end{array}$ & $\begin{array}{c}-0.62 \\
(0.03)\end{array}$ \\
\hline $\begin{array}{l}\text { Parameters of } S \\
\sigma_{0}{ }^{b}\end{array}$ & & $\begin{array}{c}0.029 \\
(0.012)\end{array}$ & $\begin{array}{c}0.013 \\
(0.085)\end{array}$ & & $\begin{array}{c}0.029 \\
(0.008)\end{array}$ \\
\hline $\begin{array}{l}\text { Profit rate } \\
\text { coefficient }\end{array}$ & & $\begin{array}{c}0.53 \\
(1.36)\end{array}$ & $\begin{array}{c}0.24 \\
(0.19)\end{array}$ & & $\begin{array}{c}0.33 \\
(0.11)\end{array}$ \\
\hline $\begin{array}{l}\text { Summary statisti } \\
R^{2} \\
N\end{array}$ & $\begin{array}{c}0.82 \\
42\end{array}$ & $\begin{array}{c}0.84 \\
42\end{array}$ & $\begin{array}{c}0.87 \\
14\end{array}$ & $\begin{array}{c}0.45 \\
56\end{array}$ & $\begin{array}{c}0.88 \\
56\end{array}$ \\
\hline $\begin{array}{l}\text { Addendum } \\
\text { LSRU }\end{array}$ & 5.9 & 5.2 & 4.6 & $\ldots$ & 5.3 \\
\hline
\end{tabular}

Source: Authors' regressions using data described in appendix A. Standard errors are shown in parentheses.

a. The dependent variable is the log change in the GDP deflator.

b. $\sigma_{0}$ is the standard deviation of the gap between lagged wages and notional wages, $\left(w_{t-1}-w_{t-1}^{\prime}\right) / \mathrm{p}_{t}^{e} \mathrm{G}_{t}$.

why there is little basis for choosing between the conventional model and our model in postwar time series.

The top panel of figure 6 gives the values of $S_{t}$ for the Great Depression, as generated in a dynamic simulation of equation 5-2, described below. The variations of $S_{t}$ during this period are an order of magnitude larger than the variations in the postwar years. And as we show, the significance of the new model becomes apparent when equations 5-1 and 5-2 are used to predict out of sample the developments in the Great Depression.

\section{The Great Depression}

Understanding the performance of the economy in the Great Depression of the 1930s has long been a challenge to economists. Most con- 
Figure 6. Wage Constraint Term, $S$

Great Depression

$S$ (percentage points)

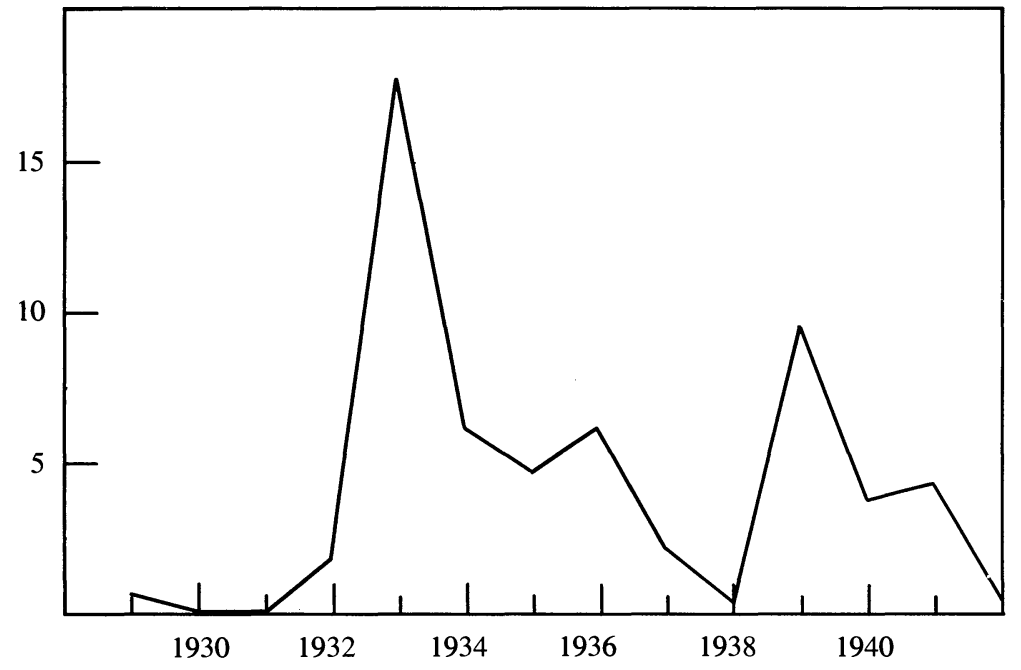

Postwar period

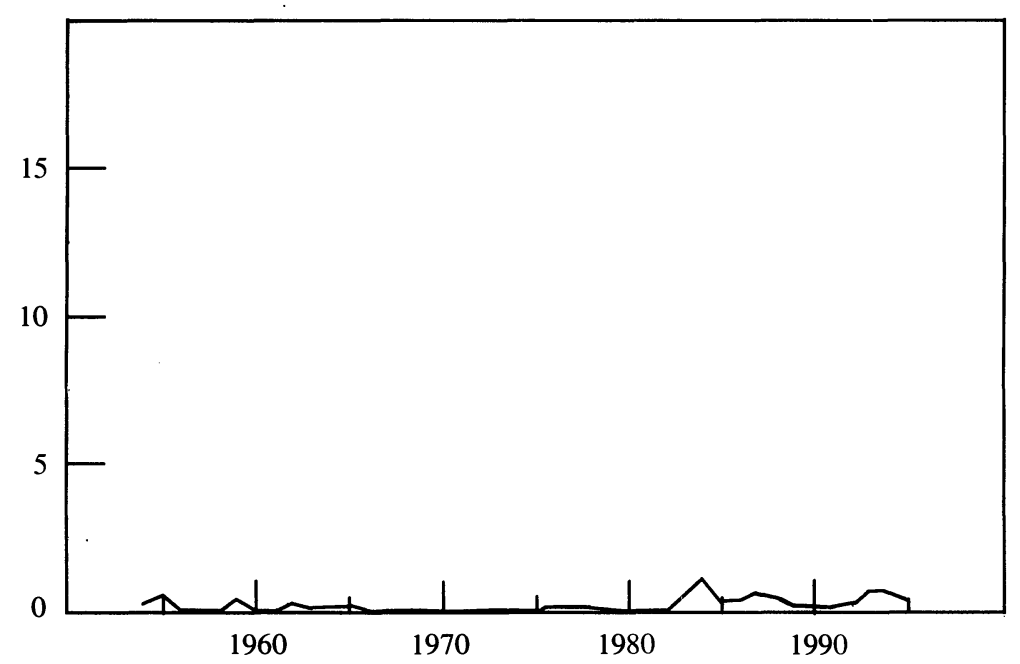

Source: Authors' estimates for equation 5-2 of table 5, using data described in appendix A. 
spicuously, theories of inflation based on the natural rate of unemployment are unable to account for developments after 1933 because the historically high unemployment rates that prevailed between that year and World War II predict accelerating deflation in natural rate models. Schultze's Brookings paper, and Gordon's discussion of that paper, both infer that in conventional models fit to the Great Depression, effects from the level of unemployment on inflation are absent and only change effects matter. ${ }^{31}$ The Great Depression thus provides a strong test of the model developed here.

OUT-OF-SAMPLE PREDICTIONS FOR THE GREAT DEPRESSION. We use equation 5-2, which has been fit to the 1954-95 period, to produce a dynamic simulation of price changes during the Great Depression. For this purpose, $S_{t}$ is constructed by assuming a value of zero in 1924 and using actual values of inflation up to 1929 , when the dynamic simulation begins. For years after 1929, the model-generated values of inflation are used to compute inflationary expectations, both in generating $S_{t}$ and in the conventional part of our inflation equation. No attempt is made to predict the years between 1942 and 1954, which comprise World War II and the Korean War, and the associated price controls. A new dynamic simulation is begun in 1954, with $S_{t}$ constructed by assuming a value of zero in 1947 and using actual values of inflation until 1954.

The predicted and actual values of inflation are given in figure 7 , where they are compared with values from equation 5-1, the conventional natural rate equation. The model with downward nominal rigidity captures the price movements remarkably well, both during the onset of the Great Depression and, more important, during the recovery years and the sharp second collapse later in the 1930s.

The severity of the downturn that started in 1929 destroyed corporate profits. In 1930 such profits fell to one-third of their 1929 levels, and the following two years produced aggregate losses. Our model predicts that under these conditions, downward rigidity would give way in many firms, and as shown in figure $6, S_{t}$ declines to its minimum value of zero in 1930-31 and the model predicts falling prices. In these early years of the decade, our model and the conventional model predict about equally well. Subsequently, the negative inflation rates begin to overwhelm other effects; $S_{t}$ becomes slightly positive in 1932 and very 
Figure 7. Dynamic Simulations of Inflation, 1929-42 and 1954-95

Model with downward rigidity

Inflation (percentage points)

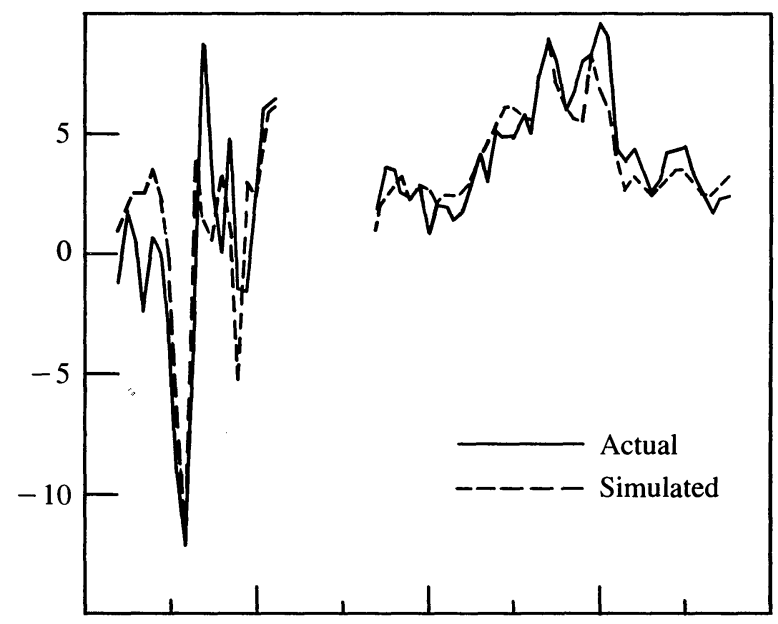

Standard natural rate model

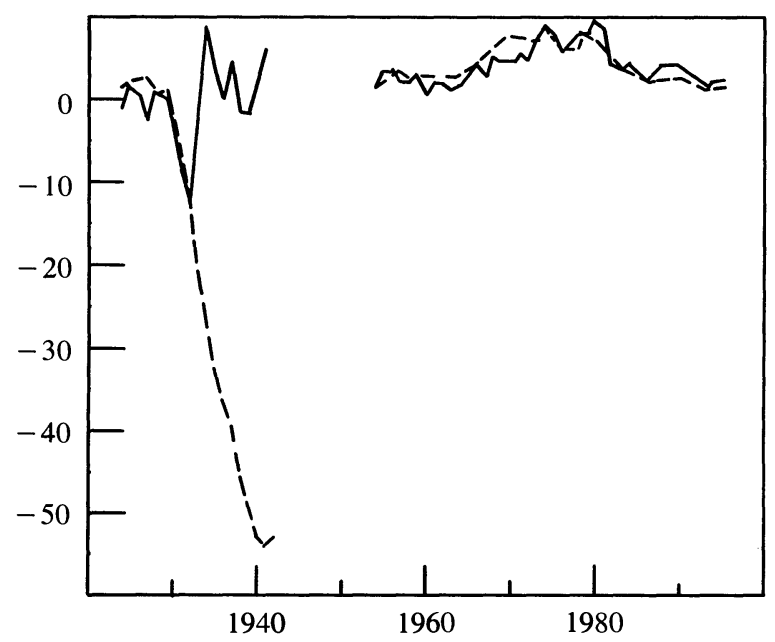

Source: Authors' dynamic simulations, using equation 5-2 for the model with downward rigidity and equation 5-1 for the standard model; both equations are found in table 5 . Data used are described in appendix A.

a. Model fit to data for 1954-95. 
large by 1933 , indicating that downward rigidity is acting strongly against the deflation predicted by the conventional variables. For 1933, the conventional mcdel predicts price declines of over 20 percent, while our model predicts inflation. Once profits turn up in 1934, our model tracks the remainder of the decade reasonably well, including the period of sharp contraction and recovery later on, when the variations in $S_{t}$ resemble those of the early 1930 s, but with a smaller amplitude.

\section{Additional Estimates and Tests}

We examine the robustness of the findings based on equation 5-2 in a number of ways. Equation 5-3 estimates the model for the Depression years alone. Considering the very few degrees of freedom available, the estimates of coefficients and parameters of $S_{t}$ are remarkably close to those in equation 5-2. An $F$ test fails to reject the hypothesis that the structure for the postwar period and the Great Depression are the same. Equations 5-4 and 5-5 combine the data for the two periods. As expected, the standard model, equation 5-4, fits very poorly and estimates no unemployment effect. Our downward rigidity model yields estimates not far from those for either subperiod, though the parameters are estimated more precisely. This is not surprising, since the Great Depression provided much more variation relevant to estimating the parameters of $S_{t}$.

We conduct several other experiments for robustness that are not reported in table 5. The change in the unemployment rate is often included in Phillips curve models. However, it is insignificant when we add it to our model for any of the periods, and has no impact on the estimates of other parameters. We also test the idea that there would be a significant amount of leakage from nominal wage constraints as a result of job switching by workers, which would eliminate wage increases normally associated with seniority, or other mechanisms that would not actually violate downward wage rigidity for individual job slots. To test for such effects, which would show up as a drift in average wages relative to the wage setting captured in our model, we adjust the model by adding a constant term to the equation for $v_{t}$. However, that parameter is estimated to be near zero and insignificant, and has no effect on the rest of the estimates.

Since the functional form for the inclusion of profits in our model is chosen arbitrarily and is not derived from the microeconomic model in the same way as the other terms, we experiment with a number of alter- 
native specifications. The postwar estimates of the role of profits are sensitive to our choice of specification. However, the ability to track the general characteristics of the Great Depression in out-of-sample forecasts is preserved in all the models that we try. Furthermore, the estimates using the combined pre- and postwar data are remarkably robust to these changes. We also test the effect of dropping the constraint that the coefficient on expected inflation equals 1.0 (the constraint that enforces the natural rate hypothesis). Without this constraint, the freely estimated coefficients are not far from 1.0 and there is no substantial change in the other parameters of the model.

Finally, the basic results reported here are also obtained with a form of the microeconomic model that allows the price-wage margin to vary in response to shocks received by firms. Such a model was used in the draft of this paper that was presented at the Brookings Panel meeting. Because that earlier version resulted in procyclical variations in the price-wage margin, and because such cyclical variation is not an agreed upon characteristic of the economy, we have modified the model as presented here. The earlier version produced all the qualitative results reported here, including the tracking of the Great Depression and the consistency of the coefficient estimates across periods.

Ideally, we would check the model against wages and hourly compensation, as well as price behavior during the Great Depression. However, the available data refer to manufacturing alone and, as the informal table below shows, their behavior is suspect, at least for our examination of aggregate inflation. The table shows the increase in real compensation and in productivity for the nonfarm business sector. The thirteen-year interval 1929-42 spans the Great Depression, ending in the first year in which the unemployment rate stayed below 10 percent. The adjoining thirteen-year intervals are shown for comparison: ${ }^{32}$

$\begin{array}{ccc}\text { Period } & \begin{array}{c}\text { Real compensation } \\ \text { (percent increase) }\end{array} & \begin{array}{c}\text { Productivity } \\ \text { (percent increase) }\end{array} \\ 1916-29 & 29.6 & 36.8 \\ 1929-42 & 70.3 & 25.6 \\ 1942-55 & 44.3 & 39.3\end{array}$

32. U.S. Department of Commerce (1966, series B72, pp. 202-03, and series A164, pp. 190-91). 
According to these data, real compensation in manufacturing rose by an astounding 70 percent over the course of the Great Depression, alongside a rise of just 26 percent in productivity. In the prosperous adjoining periods, real compensation rose by far less, while productivity rose by substantially more. Perhaps the compensation data are accurate and measure a historic increase in relative compensation for the manufacturing sector. Some increase is consistent with the growing strength of manufacturing unions during the period, although the magnitude still seems large. But regardless of whether the data are accurate for the manufacturing sector, they cannot be useful to our inquiry about aggregate inflation. So our quantitative exploration is confined to explaining price inflation.

\section{Alternative Stabilization Paths}

The empirical success with time-series estimation lends important support to the simulation model and to its demonstration that maintaining complete price stability increases the economy's sustainable rate of unemployment. We now use the empirical model to illustrate this point, by comparing economic performance under alternative inflation targets pursued by the monetary authority. In figure 8 , the economy starts with both unemployment and inflation at 6 percent. Then policy is set to reduce the inflation rate by 1 point a year until it reaches its target level. In one case the target is zero inflation, and in the other it is 3 percent inflation. Productivity growth is set at 1.5 percent a year, which is about 0.5 percent faster than the disappointing trend that has held since the 1970s, but is still only about one-half the trend achieved in the first thirty postwar years. Because we have no way to generate changes in profits for this projection, the two paths are calculated from equation $5-2$, holding profits constant in forming $S_{t}$.

For the first three years, inflation declines by the targeted 1 point a year and unemployment rises. In the fourth year, the two paths for unemployment diverge sharply as the target inflation rates also diverge. In the case of steady 3 percent inflation, the target has been reached and unemployment declines. By year five, the steady state is nearly achieved at a sustainable unemployment rate of 5.8 percent.

With a target of zero inflation, unemployment continues to rise after 
Figure 8. Alternative Stabilization Paths, Zero and 3 Percent Inflation Targets ${ }^{a}$

Unemployment rate (percentage points)

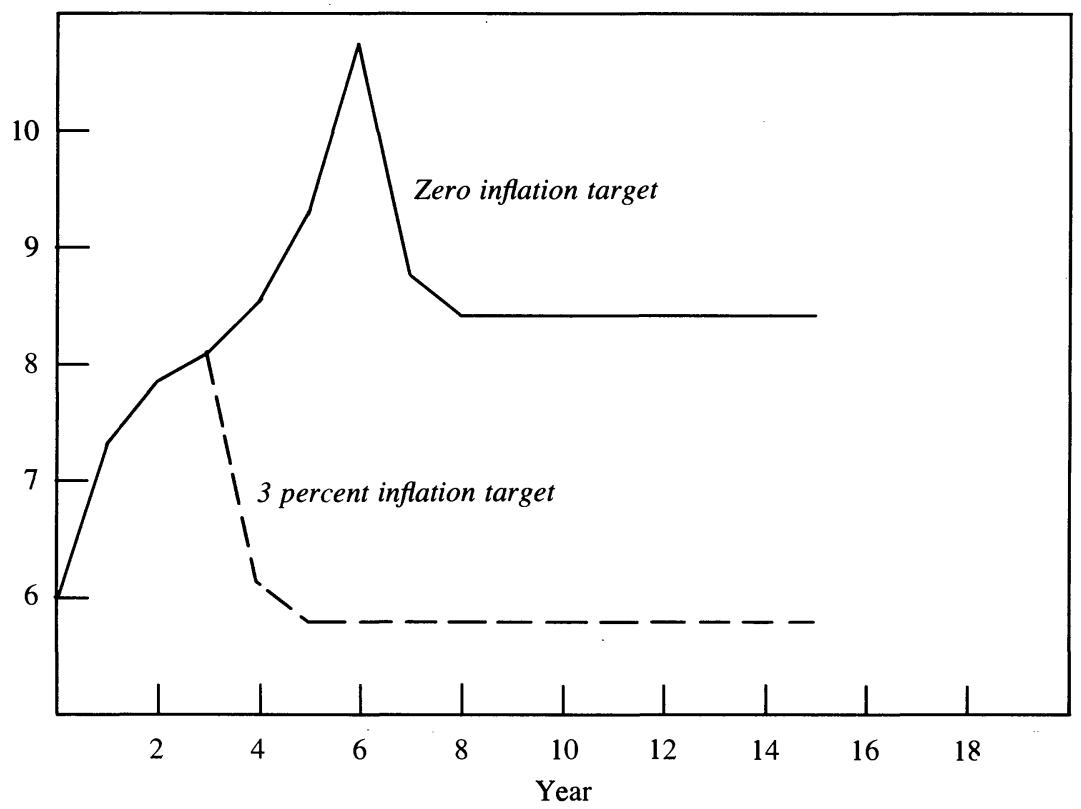

Source: Authors' dynamic projections, based on equation 5-2 of table 5.

a. Starting from 6 percent inflation.

the third year. Moreover, the effects of wage rigidity mount as inflation approaches zero, increasing the incremental unemployment cost of reducing inflation further. The zero inflation rate target is not reached until the sixth year, at which point unemployment has reached 10.8 percent. Unemployment declines gradually from that point, nearing its steady-state rate of 8.4 percent after a decade. Comparing the two paths, the sustainable rate of unemployment is 2.6 percentage points higher in the long run with the zero inflation target, a result broadly consistent with the steady-state results from the simulation model presented above.

\section{Conclusions and Implications}

We demonstrate the prevalence of downward wage rigidity in the U.S. economy and model its significance for the economy's perfor- 
mance. Downward rigidity interferes with the ability of some firms to make adjustments in real wages, leading to inefficient reductions in employment. With trend growth in productivity near recent rates, as the rate of inflation approaches zero, the number of firms constrained and the degree of their constraints increase sharply, as does this inefficiency and shortfall in employment. The difference in the sustainable rate of unemployment between operating with a steady 3 percent inflation rate and a steady zero percent inflation rate is estimated as 1 to 2 percentage points in our simulation model, and 2.6 percentage points in the empirical time-series model. The main implication for policymakers is that targeting zero inflation will lead to a large inefficiency in the allocation of resources, as reflected in a sustainable rate of unemployment that is unnecessarily high.

Some might argue that the behavior that we model characterizes a regime that will change, that a determined zero inflation policy would break down wage rigidity. We have several thoughts about this. We suspect that wage rigidity is deeply rooted, not ephemeral or characteristic of a particular set of institutions or legal structures, although these may well help to codify it and expand the relations to which it applies. The psychological studies that we cite treat as fundamental the notions of fairness and worker morale that appear to underlie nominal rigidity. Historical studies find downward rigidity present well before the existence of modern labor market laws and institutions, although whether to the same degree cannot be established from the available evidence. We observe that rigidity breaks down at the firm level when firms are under extreme duress, a condition that employees can observe and are willing to respond to; and we account for this behavior in our model. But this does not imply that rigidity in the aggregate is susceptible to a permanent regime change following analogous macroeconomic conditions. In the Great Depression, when extreme duress became widespread, downward rigidity initially gave way, but it did not break down permanently. Eventually laws and institutions were strengthened to reinforce downward rigidity. The idea that rigidity represents a particular regime that will disappear if the appropriate policies are sustained would seem to have the sign wrong.

There is a further question of whether one should want to eliminate downward rigidity, even if one could do so. We have not addressed this question in our analysis, but observe that downward rigidity pro- 
vides a brake against runaway deflation. It is a feature of labor markets that stabilizes the economy against extreme outcomes by reducing deflationary expectations and permitting real interest rates to fall, thus preventing the bankruptcies that accompany debt deflation. Rather than either denying its importance, which our analysis establishes, or anticipating that it will give way under some policy regime, we conclude that policy should be framed recognizing the existence and implications of downward rigidity.

Finally, our analysis of the macroeconomics of low inflation has a direct bearing on the public finance literature that evaluates the distortions in the tax system that arise from nonzero inflation rates. In that literature, moving to zero inflation reduces distortions that exist in a nominally defined tax system. A widely used simplification compares the present value of permanently removing these distortions with the one-time unemployment cost of getting inflation to zero. In such a comparison, even small permanent benefits outweigh large one-time costs. But our analysis shows that such a comparison is invalid. The unemployment costs are not one-time but, rather, permanent and substantial. Comparing low inflation rates with a zero inflation rate, we are convinced that the unemployment costs outweigh the costs of tax distortions. We fully appreciate the benefits of stabilizing inflation at a low rate, and advocate that as an appropriate target for monetary policy. But the optimal inflation target is not zero.

APPENDIX A

\section{Derivation of the Estimation Equation and Specification of the Estimation and Dynamic Simulations}

THIS APPENDIX presents the derivation of the estimated equations in the text, equations 8,9 , and 14 , and explains the estimation procedure and the dynamic simulations reported. 


\section{Derivation}

The derivation has two parts. The first part shows how $S_{t}$, which is the average increase in unit labor costs due to downward wage rigidity, will enter an augmented Phillips curve. The second part shows the derivation of the recursion relation of $S_{t} . S_{t}$ is defined as the average gap between expected actual and notional real wages adjusted for productivity: $S_{t}=\left(\bar{w}_{t}-\bar{w}_{t}^{n}\right) / p_{t}^{e} G_{t}$. This shift in expected real unit labor costs has the same effect on the Phillips curve as an increase in the notional wage relative to productivity. We first show that it will enter the Phillips curve in exactly the same way as the determinants of the notional wage from the wage setting equation.

Because the current wage, $w_{t}$, for each firm depends upon last period's nominal wages, downward nominal wage rigidity will cause $S_{t}$ to have a recursive component.

DERIVATION OF THE AUGMENTED PHILliPS CURVE. We use the equations of the simulation model, modified to account for productivity growth, to show how the standard price-inflation Phillips curve is derived from price equations and wage setting equations in the presence of wages constrained by downward rigidity.

The demand function for each firm is exactly the same as in the simulation model:

$$
D_{t}=\left[\left(M_{t} / \bar{p}_{t}\right)\left(p_{t} / \bar{p}_{t}\right)^{-\beta}\right] / n \text {. }
$$

The production function is altered to reflect the rate of trend productivity growth, so that

$$
Q_{t}=G_{t} L_{t},
$$

where $G_{t}$ is labor productivity.

Profit maximization by the firm yields the price, $p_{t}$, as a markup over unit labor costs:

$$
p_{t}=\frac{\beta w_{t}}{(\beta-1) G_{t}} .
$$

We now change the wage setting equation to account for long-term growth in productivity. We assume that the average real wage at other firms grows with productivity, as does $s$, the value of time when unemployed. Under these assumptions, equation 5 for the determination 
of the notional real wage can be approximated in exponential form for a representative firm as

$$
\omega_{t}^{n}=\exp \left(h-a u_{t}\right) G_{t},
$$

where $u_{t}$ is the economywide unemployment rate.

From the definition of $S_{t}$, the average nominal wage is the sum of the notional wage and the difference between the nominal and the notional wage due to wage ridigity, such that

$$
\bar{w}_{t}=\bar{w}_{t}^{n}+G_{t} p_{t}^{e} S_{t},
$$

and since $w_{t}^{n}$ is equal to $p_{t}^{e} \omega_{t}^{n}$ (given that the nominal notional wage at $t$ will be set with expectations about the price level at $t$ ),

$$
\bar{w}_{t}=p_{t}^{e}\left(\bar{\omega}_{t}^{n}+S_{t} G_{t}\right)
$$

or,

$$
\bar{w}_{t}=p_{t}^{e}\left(1+\frac{S_{t}}{\left(\bar{\omega}_{t}^{n} / G_{t}\right)}\right) \bar{\omega}_{t}^{n} .
$$

Because $p_{t}=[\beta /(\beta-1)] w_{t} / G_{t}$ by equation $\mathrm{A} 3$, the notional real wage divided by productivity can be approximated by $(\beta-1) / \beta$. As a result,

$$
\bar{w}_{t} \cong p_{t}^{e}\left(1+\frac{S_{t}}{(\beta-1) / \beta}\right) \bar{\omega}_{t}^{n} .
$$

Using (A3) for the relation between $p_{t}$ and $\bar{w}_{t}$ yields

$$
p_{t} \cong \frac{\beta}{\beta-1} p_{t}^{e}\left(1+\frac{S_{t}}{(\beta-1) / \beta}\right)\left(\bar{\omega}_{t}^{n} / G_{t}\right) .
$$

Taking the natural log of both sides of the equation and using equation A4 as the approximation for $\omega_{t}^{n}$ yields

$$
\ln p_{t} \cong \ln \frac{\beta}{\beta-1}+\ln p_{t}^{e}+\frac{\beta}{\beta-1} S_{t}+h-a u_{t} .
$$

Subtracting the natural log of $p_{t-1}$ from both sides of (A10), and noting that inflation, $\pi_{t}$, is approximately equal to $\ln p_{t}-\ln p_{t-1}$ and expected inflation, $\pi_{t}^{e}$, is approximately equal to $\ln p_{t}^{e}-\ln p_{t-t}$, yields the 
standard expectations augmented Phillips curve, modified by the presence of downward rigidity, $S_{t}$ :

$$
\pi_{t}=\pi_{t}^{e}+c-a u_{t}+\frac{\beta}{\beta-1} S_{t},
$$

where $c=h+\ln (\beta /(\beta-1))$. For our nonlinear estimation, it remains to derive the recursion relation of $S_{t}$.

\section{The Recursion Relation}

The current nominal wage depends on the nominal wage in the past as well as on the current notional wage. Since the current notional wage is a parametric function of the current unemployment rate (according to equation A4), we can express $S_{t}$ as a function of its past value and the unemployment rate. We begin with the definition of $S_{t}$ :

$$
S_{t}=\frac{\left(\bar{w}_{t}-\bar{w}_{t}^{n}\right)}{p_{t}^{e} G_{t}}
$$

It is now necessary to express $\bar{w}_{t}$ as a function of $\bar{w}_{t-1}$ and $\bar{w}_{t}^{n}$. Because $w_{t}$ is equal to $\max \left(w_{t-1}, w_{t}^{n}\right)$,

$$
\begin{aligned}
\bar{w}_{t}-\bar{w}_{t}^{n}= & E\left(w_{t-1}-w_{t}^{n} \mid\left(w_{t-1}-w_{t}^{n}\right) \geq 0\right) \\
& \operatorname{Pr}\left(\left(w_{t-1}-w_{t}^{n}\right) \geq 0\right) .
\end{aligned}
$$

We now derive the preceding result. The main argument resumes after equation A18.

$$
\begin{aligned}
\bar{w}_{t}= & E\left(w_{t}^{n} \mid w_{t}^{n}>w_{t-1}\right) \operatorname{Pr}\left(w_{t}^{n}>w_{t-1}\right) \\
& +E\left(w_{t-1} \mid w_{t-1} \geq w_{t}^{n}\right) \operatorname{Pr}\left(w_{t-1} \geq w_{t}^{n}\right) .
\end{aligned}
$$

Equation A14 can be written as

$$
\begin{aligned}
\bar{w}_{t}= & \int_{-\infty}^{\infty} \int_{w_{t-1}^{\prime}}^{\infty} w_{t}^{n} B\left(w_{t}^{n}, w_{t-1}\right) d w_{t}^{n} d w_{t-1} \\
& +\int_{-\infty}^{\infty} \int_{w_{t}^{n}}^{\infty} w_{t-1} B\left(w_{t}^{n}, w_{t-1}\right) d w_{t-1} d w_{t}^{n},
\end{aligned}
$$

where $B$ is the bivariate density of $w_{t}^{n}$ and $w_{t-1}$. Equation A15, in turn, can be rewritten as 
(A16)

$$
\begin{aligned}
\bar{w}_{t}= & \int_{-\infty}^{\infty} \int_{w_{t-1}^{\prime}}^{\infty} w_{t}^{\prime \prime} B\left(w_{t}^{n}, w_{t-1}\right) d w_{t}^{n} d w_{t-1} \\
& +\int_{-\infty}^{\infty} \int_{w_{t}^{\prime \prime}}^{\infty} w_{t}^{n} B\left(w_{t}^{n}, w_{t-1}\right) d w_{t-1} d w_{t}^{n} \\
& +\int_{-\infty}^{\infty} \int_{w_{t}^{\prime \prime}}^{\infty}\left(w_{t-1}-w_{t}^{n}\right) B\left(w_{t}^{n}, w_{t-1}\right) d w_{t-1} d w_{t}^{n},
\end{aligned}
$$

or,

$$
\begin{aligned}
\bar{w}_{t}= & E\left(w_{t}^{n} \mid w_{t}^{n}>w_{t-1}\right) \operatorname{Pr}\left(w_{t}^{n}>w_{t-1}\right) \\
& +E\left(w_{t}^{n} \mid w_{t-1} \geq w_{t}^{n}\right) \operatorname{Pr}\left(w_{t-1} \geq w_{t}^{n}\right) \\
& +E\left(w_{t-1}-w_{t}^{n} \mid w_{t-1} \geq w_{t}^{n}\right) \operatorname{Pr}\left(w_{t-1} \geq w_{t}^{n}\right) .
\end{aligned}
$$

As a result,

$$
\begin{aligned}
\bar{w}_{t}-\bar{w}_{t}^{n}= & E\left(w_{t-1}-w_{t}^{n} \mid\left(w_{t-1}-w_{t}^{n}\right) \geq 0\right) \\
& \operatorname{Pr}\left(\left(w_{t-1}-w_{t}^{n}\right) \geq 0\right) .
\end{aligned}
$$

We assume that $w_{t}^{n}$ and $w_{t-1}$ have a joint normal distribution, so their difference has a normal distribution and (A13) can be written as

$$
\bar{w}_{t}-\bar{w}_{t}^{n}=\sigma_{t} \phi\left(\frac{\bar{w}_{t-1}-\bar{w}_{t}^{n}}{\sigma_{t}}\right)+\Phi\left(\frac{\bar{w}_{t-1}-\bar{w}_{t}^{n}}{\sigma_{t}}\right)\left(\bar{w}_{t-1}-\bar{w}_{t}^{n}\right),
$$

where $\phi$ is the standard normal density function, $\Phi$ is the cumulative distribution, and $\sigma_{t}$ is the standard deviation of $w_{t-1}-w_{t}^{n}$. Making the further assumption, as an approximation, that the variances and covariances of the joint distribution of $w_{t-1}$ and $w_{t}^{n}$ are all proportional to the square of $p_{t}^{e} G_{t}$,

$$
\sigma_{t}=\sigma_{0} p_{t}^{e} G_{t}
$$

This normalization of $\sigma_{t}$ makes sense, as wages must grow with productivity and this period's wage is determined by expected prices for this period. As a result, we find that

$$
S_{t}=\frac{\bar{w}_{t}-\bar{w}_{t}^{n}}{p_{t}^{e} G_{t}}=\sigma_{0} \phi\left(\frac{v_{t}}{\sigma_{0}}\right)+\Phi\left(\frac{v_{t}}{\sigma_{0}}\right) v_{t}
$$


where

$$
v_{t}=\frac{\bar{w}_{t-1}-\bar{w}_{t}^{n}}{p_{t}^{e} G_{t}}
$$

Recursion occurs because $v_{t}$ can be expressed as a function of $S_{t-1}$ and other variables. This function is obtained by first decomposing $\bar{w}_{t-1}$ $-\bar{w}_{t}^{n}$, the numerator of $v_{t}$, into two terms: $\left[\bar{w}_{t-1}-\bar{w}_{t-1}^{n}\right]-\left[\bar{w}_{t}^{n}-\right.$ $\left.\bar{w}_{t-1}^{n}\right]$. The first term is the numerator of $S_{t-1}$, while the second term, the change in the notional wage, can be expressed as a function of the determinants of that change. Accordingly, the next step is to note the decomposition

$$
\begin{aligned}
v_{t}= & \frac{\bar{w}_{t-1}-\bar{w}_{t-1}^{n}}{p_{t-1}^{e} G_{t-1}} \frac{p_{t-1}^{e} G_{t-1}}{p_{t}^{e} G_{t}} \\
& -\frac{\bar{w}_{t}^{n}-\bar{w}_{t-1}^{n}}{\bar{w}_{t-1}^{n}} \frac{\bar{w}_{t-1}^{n}}{p_{t-1}^{e} G_{t-1}} \frac{p_{t-1}^{e} G_{t-1}}{p_{t}^{e} G_{t}} .
\end{aligned}
$$

We now make four substitutions or approximations:

-By definition, $S_{t-1}=\left[\bar{w}_{t-1}-\bar{w}_{t-1}^{n}\right] / p_{t-1}^{e} G_{t-1}$.

$-p_{t-1}^{e} G_{t-1} / p_{t}^{e} G_{t}$ is approximately $\left(1+g_{t}+\pi_{t}^{e e}\right)^{-1}$, where $g_{t}$ is the growth of productivity and $\pi_{t}^{e e}$ is the growth of price expectations.

-The term $\left[\left(\bar{w}_{t}^{n}-\bar{w}_{t-1}^{n}\right) / \bar{w}_{t-1}^{n}\right]$ is the rate of change of $p_{t}^{e} \bar{\omega}_{t}^{n}$, which is approximated as $g_{t}+\pi_{t}^{e e}-\left(a u_{t}-a u_{t-1}\right)$, using equation A4.

-Since $p_{t}=[\beta /(\beta-1)]\left[w_{t} / G_{t}\right]$ by equation $\mathrm{A} 3$, we approximate $\left[\bar{w}_{t-1}^{n} / p_{t-1}^{e} G_{t-1}\right]$ as $(\beta-1) / \beta$.

$$
v_{t} \cong \frac{S_{t-1}-[(\beta-1) / \beta]\left[\pi_{t}^{e e}+g_{t}-a\left(u_{t}-u_{t-1}\right)\right]}{1+\pi_{t}^{e e}+g_{t}},
$$

where

$$
\pi_{t}^{e e} \cong \ln p_{t}^{e}-\ln p_{t-1}^{e} \cong \pi_{t}^{e}+\pi_{t-1}-\pi_{t-1}^{e}
$$

And by assumption, inflationary expectations are formed by

$$
\pi_{t}^{e}=\alpha \pi_{t-1}+(1-\alpha) \pi_{t-2} .
$$

To this point, the model does not incorporate the feature of our simulation that relaxes the constraint against wage cuts for firms under extreme duress. To do so, we allow $S_{t}$ to decline when the share of profits $(r)$ falls, by adding $d\left(r_{t}-r_{t-1}\right)$ to equation A24 to yield 
(A27)

$$
\begin{aligned}
v_{t} \cong & \frac{S_{t-1}-[(\beta-1) / \beta]\left[\pi_{t}^{e e}+g_{t}-a\left(u_{t}-u_{t-1}\right)\right]}{1+\pi_{t}^{e e}+g_{t}} \\
& +d\left(r_{t}-r_{t-1}\right) .
\end{aligned}
$$

Equations A11, A21, A27, A25, and A26 describe the model that we estimate.

\section{Estimation}

We estimate this model on annual data for the United States from 1954 to 1995 . The profit rate is constructed as the ratio of domestic profits and IVA to GDP from the National Income and Product Accounts (NIPA). The 1947 to 1984 trend is removed from the series, since it is thought that it mainly reflects an increased reliance on debt financing by U.S. firms, rather than the declining health of individual firms. The equation that we estimate is equation A11, with an error term added to reflect errors of approximation and omitted factors. We assume that expected inflation is a moving average of the previous two years' inflation. We also assume that the error in equation A11 is i.i.d. with mean zero, except in the years of the Nixon price controls and the supply shocks of 1973 and 1979. We include dummy variables for those years to allow the error to have a nonzero mean. The Nixon price control dummies are NIXON, which is equal to 0.25 in 1971 (because the controls were introduced in the fall), 1 in 1972 (when the controls were fully operational), and 0.5 in 1973 (because in that year the controls were being eroded and exceptions were regularly allowed), and NIX$O F F$, which is equal to 1 in 1974 , the year in which the price controls were fully removed.

We compute inflation as the log change in the GDP deflator, and use the total civilian unemployment rate. Taking the average annual change, we measured trend productivity as 2.96 percent per year from 1954 to 1973 , and 0.90 percent per year between 1973 and 1995 . We smooth the transition between these two periods by allowing it to occur in equal steps over the five years centered in 1973.

The model is estimated by nonlinear least squares, which allows for the simultaneous estimation of the parameters of the Phillips curve and $S$. Thus the time series of $S_{t}$ is itself generated by the estimation process. In the estimation procedure, the history of $S_{t}$ is reconstructed for each 
evaluation of the objective function. $S_{t}$ is assumed equal to zero in 1947, and is computed using equations A21 and A27 for subsequent years. The parameters estimated are $a$ and $c$ from equation A11, $\sigma_{0}$ from equation A21, $d$ from equation A27, the coefficients on the dummy variables, and the coefficient of lagged inflation $\alpha$ in equation A26.

\section{Dynamic Simulation}

We conduct dynamic forecasts of the model for the postwar period and the Great Depression. For the postwar period, $S_{t}$ is set equal to zero in 1947 and then constructed using actual values of all variables until 1954. For years after 1954, the predicted values of inflation are used to form inflationary expectations and to construct $S_{t}$.

For the dynamic simulations of the Great Depression, we use Stanley Lebergott's (1964) unemployment series. GNP and the GNP deflator are taken from the NIPA, and profit rates are calculated from that data using pretax profits. For years before 1929, which are used to obtain start-up values, the GNP deflator constructed by John Kendrick (1961) is used in log change form to measure inflation, and profit rates are assumed unchanged. The trend rate of productivity growth was calculated as 2.1 percent for the entire prewar period. $S_{t}$ is constructed by using actual values of its determinants until 1929, after which the dynamic predictions of inflation are used to construct inflationary expectations. The results of both exercises are described in the text. 


\section{Comments and Discussion}

Robert J. Gordon: This paper by Akerlof, Dickens, and Perry provides a profound challenge to both classical and mainstream economists, who track the key macroeconomic relationships that form the basis of theory and that influence policymakers. For more than two decades, both groups have assumed that the appropriate job of policy is to "steer" real GDP or the unemployment rate toward the current estimate of the "natural rate", of real GDP or unemployment (the NAIRU). Policymakers desiring to maintain a stable inflation rate attempt to maintain the actual unemployment rate at the NAIRU, and those desiring a lower inflation rate attempt to maintain the actual unemployment rate above the NAIRU. With either set of tastes, it has been necessary for policymakers to know the NAIRU.

The NAIRU approach has created an essential unity in macroeconomics. Nominal demand disturbances (caused by monetary or nonmonetary shocks) are "neutral," affecting both output and inflation in the short (and medium) run, but only inflation in the long run. Any "mistake"' by policymakers would be self-correcting, since overexpansion would lead to inflation that would erode real balances and redirect the economy toward the NAIRU, and vice versa.

By arguing that nominal wage rigidity eliminates monetary neutrality, Akerlof, Dickens, and Perry challenge a core element of both classical and mainstream macroeconomics. No longer is a change in nominal GDP growth neutral with respect to unemployment; as the inflation rate approaches zero, a deceleration in nominal GDP growth creates a permanent increase in unemployment, rather than the tempo- 
rary increase that is usually fed into conventional measures of the "sacrifice ratio." For these authors, the sacrifice ratio no longer involves a trade-off between the permanent benefits of a lower inflation rate and the temporary cost of lower output. Instead, the cost of lower output and higher unemployment is permanent and swamps the permanent benefits of a zero inflation rate. If their argument is correct, the Fed, and indeed every foreign central bank, should abandon any attempt to achieve a zero inflation rate because the unemployment costs are so high.

Monetary neutrality is a neat and attractive proposition. It anchors much of current thinking about macroeconomic policy. The raw data in recent U.S. history seem entirely consistent with the existence of a NAIRU and with a linear short-run Phillips curve-the deceleration of inflation in 1982-87 and 1990-93 and the acceleration of inflation in 1987-90 exhibited a magnitude and a timing that are well explained by a linear Phillips curve model specified and estimated in the early 1980s, before these episodes occurred.'

What, then, do the authors provide to convince the reader that macroeconomics should abandon the proposition of monetary neutrality? The paper can be divided roughly into thirds, the first part consisting of microeconomic evidence on the existence of downward wage rigidity, the middle part consisting of a simulation model that establishes the link between downward wage rigidity and monetary nonneutrality, and the final part presenting new time-series evidence on the relationship between inflation and unemployment.

The first part of the paper reviews a wealth of interview and survey evidence, and also presents a new set of survey results for the Washington area, demonstrating the reality of downward wage ridigity. A basic reason for downward rigidity is the perceived unfairness of wage cuts, except in the special circumstances of the imminent bankruptcy of the firm that is paying the wage. The paper takes from previous research the result that wages are heterogeneous across firms and industries to an extent far beyond that which can be explained by differences in labor quality. Workers with high unexplained wage differentials earn rents, and the firms paying these high wages tend to earn above-average profits. Only when firms are in distress and profits dis-

1. One such attempt is contained in Gordon (1994). 
appear, the authors argue, will employees be willing to accept a nominal wage reduction.

This part of the paper provides convincing evidence that nominal wage reductions are rare. However, I question the relevance of this evidence for the paper's broader macroeconomic conclusions. Of course nominal wage reductions are rare in a macroeconomic environment in which inflation is positive and nominal wages, on average, grow at or above the rate of inflation. During the past three decades, increases in nominal compensation per hour of 109 percent (1965-75), 110 percent (1975-85), and 48 percent (1985-95) have been observed. In such an environment, any worker receiving a nominal wage reduction would have a right to feel aggrieved that he or she was being treated unfairly. Firms would naturally shy away from imposing nominal wage reductions, except in very special circumstances, because they would risk losing their best workers to firms that were paying out wage increases at something closer to the national average rate.

The authors' attempt to reason from evidence on nominal wage rigidity in an environment of rapid positive average nominal wage change to a hypothetical situation of zero average nominal wage change is subject to the Lucas critique. If the macroeconomic environment were different, microeconomic behavior would be different. Nominal wage reductions would no longer be seen as unusual if the average nominal wage was not growing. Workers would not see them as unfair, and firms would not shy away from imposing them, knowing that the alternative wage for workers who were tempted to quit was not growing.

Indeed, standard data show that nominal wages were not rigid in the Great Contraction of 1929-33, but rather, declined by 17 percent. The problem in the Great Depression was not that the nominal wage was rigid downward, but that it was so flexible upward! The nominal wage jumped by 20 percent in 1934 and increased by a further 27 percent between 1934 and $1940 .^{2}$

The middle part of the paper develops a simulation model that demonstrates the link between nominal wage rigidity and the long-run inflation-unemployment trade-off. The intuition behind this link is easy to see, given a distribution across firms in the equilibrium rate of real

2. U.S. Department of Commerce (1973, series B69 [CPI] and series B70 [real compensation per hour]). 
wage increase or decrease. Imagine that the growth rate of nominal demand is reduced to equal that of potential output, in an attempt by the central bank to push the inflation rate toward zero. As the inflation rate falls toward zero, firms on the left side of the distribution, for which the equlibrium real wage change is negative, find that they cannot implement a real wage reduction, since the inflation rate is approaching zero and the assumed nominal wage floor prevents a nominal wage reduction. Faced with paying a real wage above equilibrium, these firms reduce employment, and the aggregate unemployment rate increases.

The authors provide numerous variations in the simulations and discuss the sensitivity of their results to alternative choices of parameters. But the key to the model is the assumption that the nominal wage floor holds permanently, in the sense that the nominal wage is allowed to decrease by no more than 1 percent per year, no matter what the macroeconomic conditions. The nominal wage paid is a fraction $(0.99)$ of the previous nominal wage or the nominal notional (that is, equilibrium) wage, whichever is greater.

The simulation model generates the near-horizontal long-run Phillips curve of figure 3 at zero rates of inflation because of the nominal wage floor. Without the wage floor, the model generates the standard vertical Phillips curve. The value of the exercise depends entirely on one's willingness to accept the microeconomic evidence in the first part of the paper, which was accumulated in an environment in which the nominal wage was increasing by 50 or 100 percent per decade.

The reader is left with two choices. One is to give up, to simply abandon further investigation of this topic, because it requires speculation about microeconomic behavior in an environment of zero average equilibrium nominal wage increase; that is, an environment that has not existed at any time during the postwar era. The other is to look to earlier history for evidence of what happens to the economy when the average nominal wage does not increase at all.

In looking for earlier examples of macroeconomic behavior in a zero inflation environment, one needs to go back only to 1922-29, when the GDP deflator was essentially constant and unemployment-far from rising to historic highs as implied by the simulation plotted in figure 3 -averaged just 3.7 percent. An even better test of the model's predictions is provided by the recessionary decade of the $1890 \mathrm{~s}$. The nominal wage rate was exactly the same in 1900 as in 1890 . Yet that 
recession was temporary, not permanent, and was far milder than is usually believed. The cumulative GDP gap during the period 18911900 was just 2.8 percent, comparable with U.S. experience in the 1970 s and 1980s. ${ }^{3}$

The final part of the paper provides new time-series evidence on the inflation-unemployment relation. It is essential to the conclusions of this paper that the Phillips curve is nonlinear, and that the curve becomes flatter at higher rates of unemployment. I have studied the nonlinearity of the Phillips curve recently, because my colleague Robert Eisner has been proposing exactly the opposite nonlinearity. He advocates macroeconomic policies that would push the unemployment rate well below conventional estimates of the NAIRU, and to support his policy position he has come up with results that show that the Phillips curve is much less steep at low unemployment rates than at high rates.

Which is right, Eisner's concave Phillips curve or Akerlof, Dickens, and Perry's convex Phillips curve? In my view, neither is correct. The Phillips curve is resolutely linear. I have tested this by taking my standard Phillips curve, which uses the unemployment gap as its demand variable and is estimated over the period 1954-96, and inserting as an additional variable the positive unemployment gap (that is, a variable that is zero when the gap is negative and equals the gap when it is positive). The sum of coefficients (current and with four lags) on the positive unemployment gap variable is highly insignificant. As an additional experiment, I have defined a positive unemployment gap, low inflation variable that equals the positive unemployment gap in quarters in which the four-quarter change in the GDP deflator is 3.0 percent or below, and is otherwise zero. It is equally insignificant. Thus I conclude that the postwar period provides no evidence whatsoever of a nonlinear Phillips curve, either convex or concave.

Indeed, in their econometric results the authors do not provide any direct evidence that the Phillips curve is nonlinear. Instead, in table 5 they take a simplified inflation equation and add their wage constraint variable, $S$, which contributes a small improvement in fit for the postwar period. In my view, the contribution of $S$ to the postwar equation is simply to proxy for variables that are included in the construction of $S$ but are otherwise omitted from the equation, namely, the change in

3. Gordon (1993, table A-1). 
unemployment and the change in productivity. In my standard inflation equation, the statistical significance of the change in unemployment is as great as the level of the unemployment gap, and the deviation of productivity growth from trend makes a marginal contribution.

More interesting is the strong performance of $S$ in explaining inflation in the Great Depression (table 5, column 5-3). As is by now well known, the standard Phillips curve does not work for the 1930s because the large decade-long positive unemployment gap predicts an accelerating deflation after 1933, in place of the price increases that actually occurred (see figure 7, lower panel). The large positive values of $S$ observed after 1932 provide an add-on element to the predicted value of inflation that vastly improves the performance of the equation, as contrasted with the standard Phillips curve. In my own work, in which both the level and change of the unemployment gap enter, the data of the 1930s cause the level effect to vanish, while the change effect remains strong.

The ability of the authors' inflation equation to provide a unified explanation of the 1930s and the postwar period is intriguing. Yet this provides no evidence of the overall proposition of monetary nonneutrality that they emphasize as their main conclusion. Instead, the $S$ variable that provides the crucial add-on term in the 1930s combines the effects of numerous subvariables that are built into $S$, including the change in unemployment, productivity, and expected inflation. As an empirical proposition, it would be valuable to learn which of these components of $S$ provide the needed explanation of inflation in the 1930 s, and how this explanation compares in predictive ability to the standard unemployment change variable that others have used.

The 1930s do not provide any convincing evidence that nominal wage rigidity leads to permanent monetary nonneutrality, simply because wage rigidity was not the problem in the 1930s. By some measures, the increase in the real wage in the 1930s was faster than during any other decade in this century. Why nominal wages were so flexible upward is a puzzling question, but not one that the authors address.

To use history to judge the paper's overall conclusion, I have pointed to the $1920 \mathrm{~s}$, when inflation was zero and unemployment was lower than the postwar average, and to the 1890 s, when the nominal wage was constant and the recession that occurred was well within the bounds of typical postwar periods of negative output gaps, both in magnitude 
and duration. Finally, one can take the entire post-Civil War era of deflation, 1865-96, as evidence that prosperity and rapid economic growth are compatible with falling prices, not to mention constant prices. History provides useful lessons, but these authors have gone to the wrong decade to look for them.

N. Gregory Mankiw: The Federal Reserve now faces a happy dilemma: should it decide to live with inflation of about 3 percent per year, or should it try to get inflation down even further and actually reach the often stated but rarely achieved goal of price stability? This paper tries to shed light on this decision by reviving and making more concrete an old argument of Tobin. ${ }^{1}$ According to that argument, inflation greases the wheels of the labor market by allowing real wages to fall even when nominal wages are sticky downward. If the Fed were to achieve true price stability, more workers would end up with wages above equilibrium levels, and this, in turn, would result in a higher level of unemployment.

My comments start with the analysis in the paper. I then turn to the broader question for policy: if a hypothetical Federal Reserve governor happened to read this paper, should it persuade her to prefer moderate over zero inflation?

In some ways, this paper is long overdue. It was more than two decades ago that Tobin proposed that inflation greases the wheels of the labor market. But until this paper there has, to my knowledge, been no formal modeling of Tobin's idea and no attempt to gauge how large the benefits of inflation are likely to be. This paper takes three steps in the right direction. First, it presents evidence that nominal wages rarely fall and argues that previous evidence to the contrary is largely the result of measurement error. Second, it presents a model that formalizes the macroeconomic effects of downward wage rigidity. Third, it presents some econometric results aimed to convince us that these effects have practical importance for understanding the dynamics of inflation and unemployment.

The first part of the paper is the most persuasive. I am largely convinced that cuts in nominal wages are rare and that measurement problems pervade the PSID data. I do have some reservations about the 
authors' telephone survey, however, largely because people are often reticent to admit bad things about themselves. The survey results show that few people ( 2.7 percent) admit to having had a nominal wage cut, but many more ( 14.7 percent) say they know someone else who has had one. My impression is that students rarely admit to having cheated on exams when asked in surveys, but they will admit to knowing someone else who has cheated. Dissembling and self-deception are powerful human traits, especially when they serve to raise status and self-esteem. There are good reasons, based in evolutionary psychology, for why people have this characteristic, and there is substantial evidence for it as well. How much it contaminates this wage survey is hard to say.

The theoretical model is fairly straightforward and does the job that it is intended to do (although with less parsimony than I would prefer). One particular feature deserves mention: the production function $Q=L$. This linear production technology seems an unobjectionable simplification, but it has strong implications. Because this production function has constant returns to labor, the model generates the prediction of a noncyclical real wage. If this production function were replaced by a more conventional production function with diminishing returns, the model would generate a countercyclical real wage-an implication without any empirical support. I stress this fact because wages play such a central role in the theory presented here. If one is skeptical of the assumption of constant returns to labor and is convinced that the real wage is not countercyclical, then one should be uneasy about the paper's theory of the labor market.

The theoretical model assumes that wages play an important role in allocating labor, even in the short run. Put simply, whatever the wage, the firm always chooses a point on its labor-demand curve. This assumpton is controversial. As many economists have noted in the past, many workers hold lifetime jobs. In the context of a long-term relationship between employer and employee, the wage is more like an installment payment than an allocative relative price. Thus, even if wages are sticky downward, that fact may have no effect on the allocation of resources. Akerlof, Dickens, and Perry assume away this possibility.

It is with the third part of the paper, which presents macroeconometric evidence, that I have the greatest reservations. The paper offers a complicated, nonlinear Phillips curve equation which tries to approx- 
imate the inflation behavior in the theoretical model. When reading this part of the paper, I was reminded of Frank Fisher's Iron Law of Nonlinear Econometrics: don't do it. The results from this complicated, nonlinear model are disappointing. When data for the postwar period are used, the in-sample fit increases only trivially from the standard, linear model: the $R^{2}$ rises from 0.82 to 0.84 . When the data from the Great Depression are added, however, the improvement in fit using this model is much greater.

I am surprised that the authors choose to ignore two lessons that we have learned in recent decades about estimating Phillips curve equations. First, we know from the work of Robert Lucas and Thomas Sargent that the coefficients on lagged inflation need not sum to one, even if the natural rate hypothesis is correct. ${ }^{2}$ If expectations are rational rather than adaptive, the sum of the coefficients will depend on the stochastic process driving inflation. Summing to unity is a special case that holds only if inflation has a unit root. This special case may be approximately true for the postwar period, but it is unlikely to hold over the period including the Great Depression.

Second, we know from previous work on price equations that the change, as well as the level, of unemployment affects inflation. Christina Romer has recently shown that this rate-of-change effect is particularly important in understanding inflation in the interwar period. ${ }^{3}$ Yet Akerlof, Dickens, and Perry include only the level of unemploymentboth in the preferred nonlinear model and in the linear benchmark equation. They note in passing that adding the rate of change does not improve the fit of their equations, but this fact is puzzling in light of previous work.

I should note that recent experience seems inconsistent with the model developed here. If this model were correct, then a reduction in inflation, as we have seen recently, should tend to raise average wages, depress profits, and push upward the steady-state unemployment rate. Instead, the recent reduction in inflation has been associated with stagnant wages, a profit boom, and unemployment lower than many economists thought possible without reigniting inflation. The results presented in the paper give a hint of the inconsistency of the proposed

2. Lucas (1972); Sargent (1971).

3. Romer (1996). 
model with recent experience. The authors' simulations show that the nonlinear model overpredicts inflation in 1994 and 1995, the last two years of the sample.

Let me now turn briefly to the broader policy question that motivates this paper: should downward rigidity of nominal wages deter policymakers from pursuing a policy of price stability? The answer, in my view, is no.

My first reason for this judgment is one that I hope the authors would share: Tobin's idea that inflation greases the wheels of the labor market is still more an intriguing conjecture than a well-confirmed theory. This paper moves us in the direction of being able to evaluate the conjecture empirically, but there is still much to be done before an impartial observer will be convinced that downward wage ridigity has important macroeconomic effects.

In addition, even if there is downward wage ridigity in our economy, it might well decrease in a regime of price stability. To some extent, downward wage rigidity is based on workers' sense of what is fair treatment by their employers. Yet notions of fairness surely depend on the environment. In a world of price stability, falling nominal wages would be more common, and aversion to them would be reduced, at least to some extent.

It is easy to build a theoretical model in which asymmetric rigidity is a by-product of positive inflation. Imagine a world in which there are fixed costs of adjusting wages and inflation is positive. In this environment, inflation causes real wages to fall automatically over time. A firm that wants to lower the real wage that it pays does not need to pay the adjustment cost; it can just wait and let inflation do the work. By contrast, a firm that wants to raise its real wage has no choice but to pay the adjustment cost; as a result, it tends to adjust quickly. In this model, wages would look downwardly rigid, but that behavior is the result of positive inflation. Under price stability, the asymmetry in wage adjustment would disappear. ${ }^{4}$

To know whether downward rigidity would actually disappear under price stability, we would need to study some economies in which prices have been more stable than they have been in the United States. Germany and Japan over the postwar period are examples that come to

4. For a formal treatment of this idea, see Ball and Mankiw, 1994. 
mind. My impression is that these countries have not suffered substantially from their low rates of inflation. The only macroeconomic evidence that Akerlof, Dickens, and Perry offer us for their view is from the Great Depression in the United States. We should, however, be reticent to extrapolate results from a massive, unexpected deflation in order to draw conclusions about an on-going regime of price stability.

To reach a final judgment about a policy of price stability, we would need to conduct a study that is truer to the title of this paper, "The Macroeconomics of Low Inflation." The paper offers a tentative assessment about one of the many possible effects of low inflation. It concludes by acknowledging that there are benefits to low inflation, and then casually dismisses these benefits as negligible. Yet that conclusion is open to debate. Certainly, the general public has a far greater distaste for inflation than the economics profession does. ${ }^{5}$ Perhaps we are just better informed than they are; but perhaps it is the other way around.

In a recent paper, Martin Feldstein tries to quantify some of the benefits of low inflation. ${ }^{6}$ One large benefit, he argues, arises from the interaction of inflation and taxes. Many economists (though not all) believe that current policy taxes capital income more heavily than is desirable. Moreover, because the tax laws are not indexed, that distortion rises with the inflation rate. In the second-best world in which we live, the Fed can indirectly reduce the distortion from capital-income taxation by reducing the rate of inflation.

One might argue that there are better ways of fixing this problem. Rather than pursuing a policy of price stability, why not just convince the Congress to index the tax code or, better yet, switch from income to consumption taxation? Here reality quickly steps in. Convincing the Congress to write a tax code that is immune to the effects of inflation is probably no easier than convincing workers and firms to avoid money illusion when they bargain over nominal wages. It is worth a shot, but I would not hold my breath.

General discussion: A number of participants at the Panel meeting discussed the variable margins and consequent variations in real wages that were part of the model in the meeting version of the paper, and

5. See Shiller (1996)

6. Feldstein (1996). 
speculated about how that feature of the model might contribute to the results. To clarify this issue, the authors, in the published version of the paper, revised the model to incorporate constant margins, noting in the text the similarity of the results to those in the meeting version. Consequently, this part of the meeting discussion is not summarized here.

Robert Hall observed that James Tobin's case for moderate inflation as a grease that helps to accomplish real adjustments is not confined to the labor market and is consequently stronger than it appears in this paper. Takatoshi Ito added that the zero floor on nominal interest rates is more important than downward wage rigidity in explaining the Great Depression and, in general, believed that the interaction between interest rates and inflation rather than nominal wages and inflation is central to understanding economic fluctuations. Hall also suggested that the paper's focus on downward nominal wage rigidity understates the full extent of rigidities in employment relationships, where it is often difficult to rewrite any terms of employment contracts. His reading of the research by Bewley that the authors cite indicates that the rigid nature of many employment relationships makes it likely that the relationship will be broken entirely, rather than renegotiated, when modifications are needed. Hall added that in motivating nominal wage rigidity, the paper does not adequately model the bilateral nature of employment arrangements.

Turning to the empirical evidence, Hall observed that the paper receives no support from cross-country patterns. There are both low-inflation, low-unemployment countries, such as Japan, and lowinflation, high-unemployment countries, such as Germany, and the general cross-country pattern shows no relation between unemployment and either short-term or long-term inflation. He conceded that the factors leading to unemployment are not yet well understood, but thought it telling that there is no support in these data for the relationship between unemployment and inflation implied by the paper. Edmund Phelps added that he knew of a host of cross-country, time-series studies in which countries are pooled to control for institutional and other differences, and that none of these investigations have found important differences across countries as inflation rates get near zero. On the other hand, Ito reported that the idea that some inflation would help to accomplish needed real adjustments was influential in economic policy 
debates during Japan's high inflation period in the 1950s and 1960s. At the time, it was argued that inflation was useful to contain real wage growth in some of the weaker parts of the economy, where productivity growth was slow, while real wages were rising elsewhere. He noted that the inflation led to substantial real appreciation of the yen under the Bretton Woods system.

Charles Schultze did not agree that the cross-country evidence on unemployment casts doubt over the results of the paper. He noted that the key prediction of the paper is that below some inflation rate, there is curvature in the otherwise vertical, long-run Phillips curve. There is no prediction about what level of unemployment goes with the vertical portion of the curve. He observed that a host of factors, such as the structure of unemployment benefits and the degree of unionization, differ substantially across countries and are likely to affect the position of the vertical portion of the curve, but that these have nothing to say about the validity of the paper's approach. Perry added that very few observations from advanced economies at any time in the postwar period provide tests of the model, since its effects become important only below low values of the sum of inflation and productivity growth rates. While industrial countries have experienced stretches of time with inflation rates near zero, these generally occurred in periods of rapid productivity growth.

Most participants accepted the basic facts about downward rigidity in nominal wages that motivate the model. However, David Lebow questioned some of the evidence presented in the paper. He noted that the model requires the importance of downward rigidity to vary with the inflation rate, a condition that the one-time survey reported in the paper does not address. And he observed that McLaughlin's work using the PSID had corrected for measurement error in that data and had drawn different inferences about the importance of downward rigidity than did the present paper. Dickens replied that McLaughlin dealt with measurement error by adjusting the standard deviation of wage changes in the PSID and then computing the proportion of wage changes that were negative in the adjusted distribution. However, if the distribution is, in fact, asymmetric, with very few negative wage changes, measurement error changes not only the standard deviation, but also the shape of the distribution, introducing additional false negatives. Simply correcting the standard deviation does not eliminate all the false negatives, 
and so, substantially overestimates the proportion of wage changes that are negative.

Hall challenged the authors to explain the 1920s as well as the Great Depression with their model, since in the period 1920-22 prices fell without very high levels of unemployment. As a related matter, Schultze observed that downward rigidity may not have been so important in earlier years. In particular, he reported that the proportion of workers with permanent job attachments, measured by workers in jobs with current or eventual tenure of twenty years or more, was much lower in the late nineteenth and early twentieth centuries than it is now. If long-term association between a particular employer and employee is enforced by some social convention of fairness in wage setting on both sides, and if one component of fairness is avoiding nominal wage cuts, then it is perfectly consistent with the authors' framework that nominal wages were less downwardly rigid in these earlier years than they are now.

Dickens, responding to Gordon's formal comments, noted that the simulation model does allow for nominal wage cuts when firms are in distress, and would predict deflation in conditions such as those that prevailed in the early 1930s. He also pointed out that Gordon's evidence on the shape of the short-run Phillips curve is irrelevant, since the model presented does not dispute the shape of the short-run trade-off, but the location of the long-run trade-off.

Lebow noted that downward nominal wage rigidity is evidence of money illusion and that if one accepted it, one should take seriously other possible aspects of money illusion as well, such as its effect on decisions about saving and when to retire. He cautioned that the distortionary impact of inflation on people's behavior is potentially farreaching, so it is unclear whether, on balance, money illusion is an argument in favor of moderate inflation. 


\section{References}

Ball, Laurence, and N. Gregory Mankiw. 1994. "Asymmetric Price Adjustment and Economic Fluctuations.' Economic Journal 104(423): 247-61.

Bewley, Truman. 1994. “A Depressed Labor Market, as Explained by Participants." Book manuscript. Yale University, Department of Economics.

Bewley, Truman, and William Brainard. 1993. "A Depressed Labor Market, as Explained by Participants."' Unpublished paper. Yale University, Department of Economics (February).

$\rightarrow$ Bils, Mark. 1987. The Cyclical Behavior of Marginal Cost and Price. American Economic Review 77(5): 838-55.

$\rightarrow$ Bound, John, and Alan B. Krueger. 1991. "The Extent of Measurement Error in Longitudinal Earnings Data: Do Two Wrongs Make a Right?' Journal of Labor Economics 9(1): 1-24.

Campbell, Carl M., and Kunal Kamlani. 1995. "The Reasons for Wage Rigidity: Evidence from a Survey of Firms.' Unpublished paper. Colgate University, Department of Economics (February).

Card, David, and Dean Hyslop. 1996. “Does Inflation Grease the Wheels of the Labor Market?' Paper prepared for Monetary Policy and Low Inflation Conference. National Bureau of Economic Research, Cheeca Lodge, Islamorada, Florida (January 11-13).

Davis, Steven J., John C. Haltiwanger, and Scott Schuh. 1996. Job Creation and Job Destruction. Cambridge, Mass.: MIT Press (forthcoming).

Dickens, William T. 1986. "Wages, Employment and the Threat of Collective Action by Workers.' Working Paper 1856. Cambridge, Mass.: National Bureau of Economic Research (June).

- 1995. “Do Labor Rents Justify Strategic Trade and Industrial Policy?', Working Paper 5137. Cambridge, Mass.: National Bureau of Economic Research (May).

$\rightarrow$ Duncan, Gregory J., and Daniel H. Hill. 1985. " An Investigation of the Extent and Consequences of Measurement Error in Labor-Economic Survey Data., Journal of Labor Economics 3(4): 508-32.

Feldstein, Martin. 1996. "The Costs and Benefits of Going from Low Inflation to Price Stability.', Working Paper 5469. Cambridge, Mass.: National Bureau of Economic Research (February).

Gordon, Robert J. 1981. “Comment.'” BPEA, 2:1981, 581-88.

-1993. Macroeconomics, 6th ed. New York: Harper Collins.

- 1994. "Inflation and Unemployment: Where is the NAIRU?', Paper prepared for Meeting of Academic Consultants, Board of Governors of the Federal Reserve System (December).

$\rightarrow$ Hall, Robert E. 1988. "The Relation between Price and Marginal Cost in U.S. Industry.', Journal of Political Economy 96(5): 921-47. 
$\rightarrow$ Hanes, Christopher. 1993. "The Development of Nominal Wage Rigidity in the Late Nineteenth Century." American Economic Review 83(4): 732-56.

- 1996. "Firm Characteristics and Nominal Wage Rigidity in the Downturns of 1983, 1929, and 1981." Unpublished paper. University of Pennsylvania, Department of Economics (February).

Holzer, Harry J. 1996. Employers, Jobs and Hiring of Less-Educated Workers. New York: Russell Sage Foundation.

Kahn, Shulamit. 1995. "Evidence of Nominal Wage Stickiness from Microdata.' Unpublished paper. Boston University, School of Management.

$\rightarrow$ Kahneman, Daniel, Jack L. Knetsch, and Richard Thaler. 1986. "Fairness as a Constraint on Profit Seeking: Entitlements in the Market.' American Economic Review 76(4): 728-41.

Kendrick, John W. 1961. Productivity Trends in the United States. Princeton, N.J.: Princeton University Press.

Lebergott, Stanley. 1964. Manpower in Economic Growth: The American Record since 1800. New York: McGraw-Hill.

Lebow, David E., David J. Stockton, and William L. Wascher. 1995. "Inflation, Nominal Wage Rigidity, and the Efficiency of Labor Markets." Finance and Economics Discussion Series 94-45. Washington: Board of Governors of the Federal Reserve System, Division of Monetary Affairs (October).

Leonard, Jonathan S. 1987. "In the Wrong Place at the Wrong Time: The Extent of Frictional and Structural Unemployment.' In Unemployment and the Structure of Labor Markets, edited by Kevin J. Lang and Jonathan S. Leonard. New York: Basil Blackwell.

Lucas, Robert E., Jr. 1972. "Econometric Testing of the Natural Rate Hypothesis." In The Econometrics of Price Determination, edited by Otto Eckstein. Washington: Board of Governors of the Federal Reserve System and Social Science Research Council.

McLaughlin, Kenneth J. 1994. "Rigid Wages?' Journal of Monetary Economics 34(3): 383-414.

$\rightarrow$ Mellow, Wesley, and Hal Sider. 1983. "Accuracy of Response in Labor Market Surveys: Evidence and Implications.' Journal of Labor Economics 1(4): 331-44.

Mitchell, Daniel J. B. 1985. "Wage Flexibility: Then and Now.' Industrial Relations 24(2): 266-79.

$\rightarrow$ O’Brien, Anthony Patrick. 1989. “A Behavioral Explanation for Nominal Wage Rigidity during the Great Depression." Quarterly Journal of Economics 104(4): 719-35.

Romer, Christina D. 1996. "Inflation and the Growth Rate of Output.' Working Paper 5575. Cambridge, Mass.: National Bureau of Economic Research (May). 
$\rightarrow$ Samuelson, Paul A., and Robert M. Solow. 1960. "Problems of Achieving and Maintaining a Stable Price Level: Analytical Aspects of Anti-inflation Policy.' American Economic Review, Papers and Proceedings 50(2): 177-94.

$\rightarrow$ Sargent, Thomas J. 1971. "A Note on the 'Accelerationist' Controversy.', Journal of Money, Credit, and Banking 3(3): 721-25.

Schultze, Charles L. 1959. "Recent Inflation in the United States.' Study Paper 1. Joint Economic Committee, 86 Cong. 1 sess. (September). 521-92.

Shafir, Eldar, Peter Diamond, and Amos Tversky. 1994. “'On Money Illusion.' Unpublished paper. Princeton University, Department of Psychology (February).

Shea, John. 1996. "Comment on Does Inflation Grease the Wheels of the Labor Market? by David Card and Dean Hyslop.', Prepared for Monetary Policy and Low Inflation Conference. National Bureau of Economic Research, Cheeca Lodge, Islamorada, Florida (January 11-13).

Shiller, Robert J. 1996. "Why Do People Dislike Inflation?" Working Paper 5539. Cambridge, Mass.: National Bureau of Economic Research (April).

$\rightarrow$ Tobin, James. 1972. "Inflation and Unemployment." American Economic Review 62(1): 1-18.

U.S. Department of Commerce. 1966. Long Term Economic Growth, 18601965. Washington: Department of Commerce.

1973. Long Term Economic Growth, 1860-1970. Washington: Department of Commerce. 